\title{
3. When systems collide: the 2001 Census at a Northern Territory outstation
}

\section{Frances Morphy}

\section{Introduction}

In August 2001 I observed the conduct of the national Census at an outstation community (henceforth community A), serviced by a homelands association (henceforth HA) which is based at the Aboriginal settlement of B in the Northern Territory. The purposes of this research were twofold: to evaluate the IES as it was applied in this particular context, and to assess the quality of the data that were collected.

This study is being published under terms of the Census and Statistics Act 1905 Undertaking of Fidelity and Secrecy, which imposes strong principles of confidentiality to protect the anonymity of census respondents. Because community A is small and its residents would be readily identifiable (at least locally) if it were named, the area in which this case study took place is left deliberately vague, and communities are referred to by letters of the alphabet rather than by names. The local Indigenous language is not referred to by name, and where Indigenous language terms occurred in the quotations cited, they are replaced by an English translation in square brackets. The kinship terms of the local system have been replaced by the short-hand forms conventionally used in anthropological publications (see explanation of kinship terminology and abbreviations on p.ix ). None of the actors in this story are identified by name: officers of the census are referred to by an acronym for their function, and other individuals are referred to by a letter, or as 'person $l^{\prime}$ in a household (where applicable). The dwellings are not individually identified by number. The data on the composition of the study community and of its households are described as if they were actual examples, in order to avoid tortuous syntax, but they should be understood for what they are: artificially constructed data sets that do not correspond to the data on the census forms for the community. The examples are hypothetical, but constructed to bring out the structures and issues that emerged clearly from the actual census data.

The first three major sections of the chapter describe in some detail the recruitment and training of the enumerators and the enumeration process itself. The intention is to provide an ethnographic account of the process in its context, as a background to the main findings and recommendations. Although the IES has been in existence in various forms since the 1976 Census (see Taylor, this volume), there is a dearth of detailed research on its implementation on the ground, and on its effectiveness as a strategy for obtaining complete and accurate information on Australia's Indigenous population.

David Martin and John Taylor, in their observation and analysis of the 1986 and 1991 Census enumerations at the remote community of Aurukun on Cape York Peninsula, found a systematic under-enumeration of children and young adults, and identified several 
contributing factors, most significantly the mismatch between standard definitions of the 'household' and the 'family' and the facts of Aboriginal social organisation on the ground, and the relatively high mobility of Aboriginal people, both between households and within particular regions (Martin \& Taylor 1995: 13, 14-17).

It will be argued in the fourth section that, considered purely as a head count, the enumeration strategy employed at community A in 2001 was largely successful. The reasons for its success are discussed: it is important to understand the reasons for success as well as for failure.

The quality of the data collected is another matter. Particular attention is given, in the fifth part of the chapter, to continuing problems with the definition of 'household' and 'family', and with the questions on the two forms - the SIHF and the SIPF- that compounded the problem of collecting reliable and meaningful data on household structure. In the final section, the quality of the other data is examined.

At a more general level, in these final two sections of the chapter, consideration is given to the kind of information that the ABS is attempting to collect in the census, and whether the design of the forms and of the questions they contain could be better tailored both to the intended respondents and to the goals of the census. The chapter concludes with some general recommendations that flow from the data and the analysis.

\section{The census enumeration in its regional context}

The rough estimate for the current Indigenous population of the SLA in which community A is located, derived from the Community Housing and Infrastructure Needs Survey (CHINS) that was conducted immediately prior to the 2001 Census, is 10,000 people. ${ }^{1}$ All of this area is remote, and most of its Aboriginal inhabitants are 'traditionally oriented' (to use a convenient shorthand term). The major communities are accessible by reasonable roads in the dry season, but many outstations can be reached only by many kilometres of rough track, or by light aircraft.

The CFO responsible for the enumeration in this SLA planned for a rolling census, with different communities being enumerated at different times, starting in the second half of July and ending by census day itself. This strategy was dictated by the logistics of training the CCs and local Indigenous interviewer-collectors (henceforth enumerators), and processing the results of the enumeration. The schedule was badly disrupted by the deaths and subsequent funerals of two people at two different communities within the SLA. These events delayed or halted the training of the enumerators and the enumeration itself. This was unfortunate for the $\mathrm{CFO}$, for whom it created something of a logistical nightmare.

As will be shown in more detail below, the enumeration in this region was carried out on the basis of persons actually present at a dwelling at the time of the enumeration; that is, according to the standard census procedure. I will argue that if it is consistently administered by enumerators with detailed local knowledge, this strategy is less inherently error-prone and more amenable to verification than the alternative strategy adopted in other areas of the Northern Territory, that of a 'usual residents' count. 


\section{The community of A: a snapshot view at census time}

The population of community A fluctuates from around 20 (when there is a large ceremony taking place elsewhere) to over 250 (when there is a ceremony taking place at the community); its normally resident population is in the region of 100 people. At the time of the enumeration about 50 per cent of the people listed as 'living here' on the SIHFs were away, at a location where a major funeral that had just taken place, or visiting relatives living elsewhere in the area. But the community was also host to a number of visiting relatives from the immediate region, and from three other communities (C, D and E) outside the immediate region.

The community is structured around the members of two related patrilineages (lineage $\mathrm{X}$ and lineage $\mathrm{Y}$ ) on whose land the community lies. $\mathrm{X}$ and $\mathrm{Y}$, the men from whom these two lineages are descended, are classified as brothers. Fig. 3.1 shows the kin relationships, in simplified form, of the people designated as 'person 1' for each occupied dwelling. The census does not capture (because it does not seek to) these inter-household relationships, but it is arguable that the data collected by the census on the composition of individual households make sense only in the context of this larger picture.

\section{Fig. 3.1 Kin relationships between people designated as 'person 1' for each occupied dwelling, community A, Census 2001}

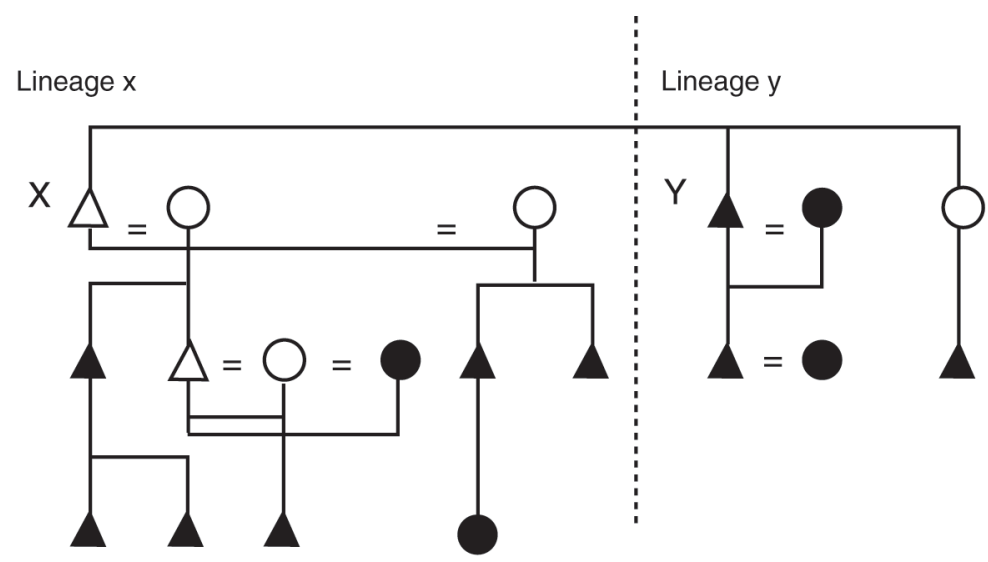

$$
\begin{array}{rll}
\text { Key: } & \bigcirc & \text { female } \\
& \Delta & \text { male } \\
& & \text { person 1 } \\
& = & \text { marriage }
\end{array}
$$

At the time of the census there were 13 occupied dwellings in the community. The census enumeration took place over three days, between 6 and 8 August. During this period the community was preparing for the funeral of an infant who had died the previous week, and it received a visit from a candidate for one of the two major political parties, canvassing for votes in the upcoming Northern Territory election. 


\section{Putting the census team in place}

For the purposes of the census, the settlement of B and the outstations serviced by the HA are counted as two separate Indigenous Areas (IAs), each with its own CCs. For the HA communities the CFO had appointed two CCs, one local Indigenous and one nonIndigenous, both HA employees. They had different responsibilities: the non-Indigenous CC was in charge of logistics - chartering planes, keeping to the budget, and so on. The Indigenous CC was responsible for overseeing the administration of the census on the ground, and for recruiting and helping in the training of the enumerators. The CFO envisaged his own role as strategic - coordinating the enumeration in the region as a whole, recruiting and training appropriate CCs, and keeping a watching brief on the various stages of the process and the training of the enumerators.

\section{The community census team}

At community A there were six enumerators (henceforth E1-6), all but one of whom were residents. The non-resident (E1) was another HA employee who is the son of a sister of X and Y. He acted as the community contact and de facto CC for the exercise. Therefore all the enumerators were well known to other community members, and had detailed knowledge of who lived where, how everyone was related to each other, and of people's present whereabouts.

Fig. 3.2 shows in simplified terms how the enumerators are related to each other and to the apical ancestors ( $\mathrm{X}$ and $\mathrm{Y}$ ) of the two major lineages represented at the community. Both E1 and E2 are ZC (sister's children) of X and Y. E2 is the most senior male ZC to the landowning group - a position of some importance in the local social system. E3 is his wife. E2, E4, E5, and E6 are all teachers in the school. E4 and E5 are granddaughters of X, and E6 is one of Y's granddaughters. The significance of these facts will emerge in due course.

Fig. 3.2 The kin connections of the community A enumerators, 2001 Census

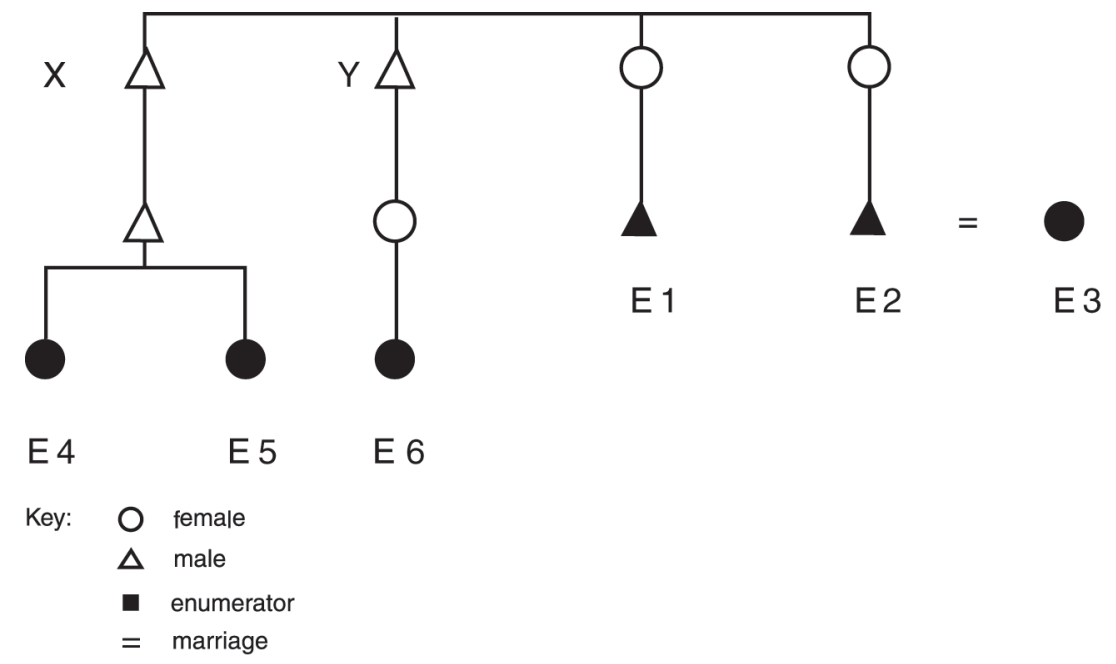




\section{Training}

I chanced to meet El in the local town centre on Friday 3 August, the day after I had arrived from Canberra. The CFO had already informed him that I was coming to community A to observe the census. He told me that he was one of the enumerators there, that all the enumerators had received their training, and that he was driving down to the community to start the enumeration on Monday (i.e. on the day before census day itself). I surmised therefore that I had missed out on the training and that it had been completed despite the disruption caused by the funerals. It appeared that my only access to information about the training process would be through debriefing the CFO and (if possible) the CCs and enumerators. Accordingly, I arranged to see the CFO on the following day. The account of the training process given below is based on what I learned at that meeting, and on a later meeting with the $\mathrm{CFO}$ after the enumeration at community A had been completed.

The CFO told me that the training of the CCs and the compilation of the Dwelling Check Lists for B and the HA outstations had been successfully carried out. The CCs had a map of each community that had to be covered, and a SIHF had been allocated for each occupied dwelling, and each had been given a Census Record Number (RNO). The CCs had been taken through their responsibilities and had been given a set of principles to work to. The Indigenous $\mathrm{CC}$ for the $\mathrm{HA}$ had been given responsibility for recruiting the enumerators for the HA communities because, the CFO reasoned, he was the person with local knowledge about who could speak to whom and how to get the job done most efficiently. He had suggested that the enumerators be organised to work in teams of two, to avoid problems of people having to speak directly to 'poison' (avoidance) relations.

It was the training of the enumerators that had been disrupted by the funerals. There had been one day of training at community B, in which the enumerators had been shown the training video. It was shown to them all the way through without interruption, in order to give them an overview of the procedure. The emphasis in the training that did occur was on procedure, on ensuring that the enumerators explained properly to the interviewees what the census was, and on the issues of confidentiality and the security of the data. They also spent some time discussing the questions which the CFO predicted would cause difficulties: the questions on kinship (on the SIHF, and Q. 4 and Q. 5 on the SIPF-see Appendices B and C), and Q. 39 on the SIPF, which asks whether the respondent agrees to having their name and address and other information from their form kept in the National Archives and then made publicly available after 99 years.

The CFO was doubtful that the kinship questions would yield useful data, because he was aware that local Indigenous kinship terms and English terms are different. The enumerators were instructed use to English kinship terms first, and to use local terms only in cases where clarification was needed. The CFO went through the basic English kin terms to ensure that the enumerators knew the meaning of terms such as niece, nephew, uncle and aunt as well as of the more core kinship terms of the English (henceforth Anglo-Celtic) system.

The CFO spent some time with the enumerators on Q. 39, explaining its meaning and getting them to practice asking each other the question and to devise a local-language version to use during the enumeration. His main concern was that the taboo on the use of 
the names of dead people would lead people to answer 'no' to the question, so the emphasis given was to the forms being locked away in Canberra for a considerable period of time.

Because of the interruption to their training, the enumerators had not had the opportunity to familiarise themselves with the forms in detail, nor to practise going through them. On the Monday the $\mathrm{CFO}$ was planning to go to community A with the Indigenous $\mathrm{CC}$ and E1 to finish the training. His intention was to let the $\mathrm{CC}$ and El conduct the training; he would intervene only as necessary, if something had been missed or clarification of some point was needed.

\section{From training to doing}

I arrived at community A on the morning of Monday 6 August in advance of the census party, and went to the school, where the other enumerators were gathering. The CFO, the $\mathrm{CC}$ and El arrived shortly thereafter by vehicle. Everyone was there except E2, who came about half an hour later.

The session proceeded. It quickly transpired that the enumerators were going directly to filling out the SIHFs, apportioning them between themselves as they went. The CFO and I noticed this separately, more or less simultaneously. He decided to allow further training to proceed 'on the job'. He continued to observe what the enumerators were doing, and intervened with instructions if he saw something not being done correctly, or if he was asked directly for advice. The CC and El were also advising the other enumerators.

Household members and visitors were listed from memory on each SIHF in turn, and also absent members of households (who were marked 'no' for a SIPF). These lists were not inviolate: later on, as the enumerators went round the houses and discovered in more detail who was there and who was away, the yes/no column was changed, as people were added or subtracted.

The CFO instructed explicitly that the family name should go on the top of the SIHF, then the head of the household should be listed as person 1. This person, he suggested, would usually be the father, then the mother and rest of family should follow. He reminded the enumerators that for every person the second name had to be filled in as well as the first.

The CFO also instructed explicitly about where the RNO and dwelling number should go (the enumerators were not filling those in until he told them to). The enumerators went to the map to find the dwelling number (the lot number), and then cross-referenced to the Dwelling Check List to find the assigned RNO. I was having trouble with this system, but it appeared to cause no difficulty to the enumerators.

The SIHF also asks for the age of each person and their relationship to person 1 . The enumerators used the school roll for the ages of the children (and the teachers), but everybody else's age was a guesstimate. El had compiled a list of everyone's ages derived from local clinic records, but he had left it behind at the HA office in community $\mathrm{B}$. He commented that this did not matter, because the ages could be fixed up at the office later.

There was some discussion about how to translate local kin terms into their English 'equivalents'; this topic was to recur throughout the enumeration. 'Wife', 'husband', 'son', 
and 'daughter' were unproblematic: everyone was familiar with how these are applied, even though they do not correspond to local terms. El reiterated that English terms had to be used, not local terms. The question of kinship and how it was reflected on the SIHFs and SIPFs is discussed in some detail below.

El explained that a SIPF was needed for everyone on the SIHF who was present at the time of the enumeration. 'Even the little children?' he was asked, to which he replied in the affirmative.

There was considerable discussion about how to treat visitors and absent residents: both the enumerators and the $\mathrm{CFO}$ were aware of the complex possibilities. E4 asked what to do about visitors from other communities. The CFO said visitors should be included on the SIHF of the dwelling at which they were staying, and marked as ' $V$ '. They should be asked if they had been counted anywhere else, and that if not they should have a SIPF filled out. In cases of doubt it was better to be on the safe side and do a SIPF, otherwise they might be missed altogether. One of the women expressed shyness about asking visitors for their details.

The CFO was also asked: 'How can you ask questions if someone is not here?' The questioner had in mind someone who was away on a trip, and who would be staying in a hotel. The CFO said that anyone like that would be counted at the hotel on census night, so they should go on the SIHF, but should not have a SIPF done for them. More generally, anyone who was away in a place where they would be counted should not get a SIPF. He was asked: What about people who are away at community C or D? The CFO suggested doing SIPFs just in case they got missed there. What about people who would be coming in tomorrow for the funeral of the baby? The CFO suggested doing a SIPF if they had not been counted anywhere else and if the dwelling was still in the process of being enumerated. But if the enumeration of the house had been completed they should not be added.

E1 suddenly remembered the tent in the front yard of one dwelling. It was normally occupied by the mother-in-law and father-in-law of 'person 1' at that dwelling, who were on an extended visit. They were away at community B, but had left initially to attend a funeral ceremony elsewhere. The CFO's view was that since the tent was not a permanent dwelling, and its usual residents were in any case visitors to the community, it should not be registered, and so it had no SIHF, and no SIPFs were attached to it. Its absent residents were not included as visitors on the SIHF for the dwelling.

After all the household forms had been completed, the CFO suggested counting the number of SIPFs needed for each dwelling and putting them in an envelope with the SIHF. El and the CFO both stressed several times that the SIPFs had to be filled in at the house wherever possible.

During this process at least one extra person was remembered for one house. There was some further discussion about people who were currently down as 'yes' but who turned out not to be there. The CFO suggested that if they did not come back during the process of enumeration they should be changed to 'no', and that no SIPFs should be done for them. At this point, one dwelling was listed as a vacant dwelling because all the occupants were away. However they returned during the process of enumeration, so the status of the dwelling was changed and SIPFs were done for the returned occupants. 
The households were initially divided up between the enumerators as follows:

- E2 and E3 took the forms for their own dwelling and for three of the dwellings occupied by descendants of $\mathrm{X}$;

- E1 and E6 took the forms for the other four houses occupied by descendants of Y (including their own dwellings, or, in El's case the dwelling he was 'visiting' at);

- $\mathrm{E} 4$ and E5 took the forms for the other four houses occupied by descendants of $\mathrm{X}$ (including their own dwellings).

Thus the workload was distributed fairly evenly, and everyone except E2 and E3 was assigned to their own 'side' of the community. E2, the most senior ZC to the apical ancestors of the two lineages, was assigned dwellings from both sides. One of the dwellings assigned to him turned out to be the most problematic in terms of the enumeration, because it contained some visitors from community $\mathrm{E}$ who were not all that concerned with - indeed who actively evaded-being counted. ${ }^{2}$

As far as I am aware, the final page of the SIHF (number of bedrooms, number of vehicles, etc.) was not filled in at this session, and I do not know when these details were added. I assume that the characteristics of the dwellings could have been added later from HA housing records, and the enumerators would have had a good idea of how many vehicles there were in the community and who owned them.

E1, in his decision to get everyone to complete the SIHFs at this session, was operating on the assumption that the training of the enumerators had been completed at B earlier. In a sense this assumption rested on a minor failure of communication between him and the CFO. The CFO later told me that the 'training' session described above was a unique occurrence: the enumeration had not proceeded at any other community in quite this way. When they set off to begin the enumeration, the enumerators had still not gone through the SIPF in detail, or familiarised themselves with the questions.

However, El was operating on another, correct, assumption: that he and his fellow enumerators knew their community well enough to fill in the SIHFs before proceeding to the enumeration proper. In doing so, they spared the interviewees a lengthy part of the process entailed in following the 'proper procedure' (see Will Sanders, this volume). The filling in of the SIHFs at this point turned out to be an advantage rather than a disadvantage: this point will be revisited below.

The session was indeed a training session in some respects. At the end of it, the CFO could be confident that the SIPFs would be correctly identified, and properly cross-referenced to their SIHFs. Between them, the CFO and the enumerators established a clear set of procedures for dealing with absent residents and visitors: the enumerators were alert to the possible permutations and the CFO held to a clear set of principles, based on the standard enumeration procedure, which he applied consistently to these permutations. They also had discussions that were as useful as they could be (which is to say not very) on the translation of kin terms. 


\section{The enumeration proceeds}

I was able to observe parts of the enumeration directly at ten dwellings (one visit each to nine dwellings, and two to the remaining dwelling). Only three of these visits were complete enumerations, because at every other house visited there were some people off hunting (or away from the dwelling for other reasons) and the enumerators followed the strategy wherever possible of returning to households to catch people rather than filling out the SIPFs in their absence. They also filled in SIPFs for people who they found at someone else's dwelling (if they had not already been enumerated), and later filed them with the correct SIHF.

\section{Day one}

On the afternoon following the filling in of the SIHFs, I went with El and E6, who made their initial visits to three dwellings. They also went briefly to E2 and E3's dwelling and helped them to fill in the SIPFs for their own household. We finished in the early evening. The CFO and CC had stayed on for part of the afternoon, and the CFO dropped in on each of the three pairs of enumerators to check on progress and to field queries. Of the dwellings visited on this day, only one was completely enumerated.

The interviews on the first day took longer than on subsequent days. The enumerators were familiarising themselves with the SIPF as they went, and in the process were trying to work out what some of the questions meant. ${ }^{3}$ They also began to devise standard replies to some questions.

\section{Day two}

The following day (census day itself) I went back with El to one of the dwellings we had visited the previous day. El's aim was to complete the SIPFs for this dwelling, which had 22 people on the SIHF: six residents who were actually there, 10 absent residents, and six visitors from community D. We had missed the visitors and several 'usual residents' on the previous day, because they were out fishing, but we got there early enough to catch them this time. El was assisted once more by E6, who lives in that dwelling. E1, E6 and I then went to the last dwelling on their list to conduct the enumeration there. By the time we finished there it was lunchtime.

In the meantime, the other enumerators had made their initial enumerations in all but three of the dwellings designated to them. After lunch everyone except E2 met back at the school 'office', where the envelopes were being deposited as the forms were completed. E1 was already in the role of chief enumerator for the lineage $\mathrm{Y}$ side of the community. During this session $\mathrm{E} 4$ began to assume the equivalent role for the lineage $\mathrm{X}$ side of the community, and they continued in these roles for the rest of the enumeration exercise. Working together, El and E4:

- checked that the SIHFs and SIPFs were in their correct envelopes (some were not);

- checked the SIHFs against their completed SIPFs to determine who had not yet been 'caught'; 
- double-checked against the school register to make sure that all preschool and schoolage children resident in the community had been covered;

- amended the SIHFs in the light of their now up-to-date information about absent and newly present residents and visitors;

- $\quad$ assigned SIPFs for people who had been missed so far (including the entire household of the dwelling which had previously been classified as vacant, and one as yet unenumerated dwelling);

- $\quad$ apportioned the remaining work.

El also began the task of making the responses to certain questions on the SIPFs consistent. For example, all schoolchildren and preschoolers were put down as speaking English 'not well'. El commented to me after the enumeration was complete that they had been learning how to fill in the SIPF during the process of enumeration. He was aware that as a result the answers to certain questions were not filled in consistently across the whole enumeration, and he did his best to remedy this after the fact, during this and a later checking session.

Following the checking session I went with El and E4 to a dwelling that had been on E4 and E5's original list, but which they had not had time to get to the day before. El and E4 managed to complete the enumeration of the dwelling in a single session, and they also persuaded one of the community E visitors (who was on the SIHF of another dwelling, but was sitting with his brother at this dwelling at the time) to fill in his SIPF. It was later added to the appropriate envelope. We then moved to the dwelling that had been listed as vacant on the previous day, and a complete enumeration of its returned occupants was successfully achieved. It was now evening again, so work stopped for the day.

\section{Day three}

The day began with an announcement over the community megaphone that one of the local candidates in the upcoming Northern Territory election was coming that morning to canvass the community. People were urged to attend, and were keen to do so, and the enumerators were anxious to complete their task beforehand. E1 and E2 were heavily involved in preparations for this visit, and so three of the female enumerators (E4, E5, and E6), with me in tow, went as a group to continue the mopping up of the remaining 'missing persons'.

We proceeded first to a dwelling where some of the occupants had not yet been enumerated. Person 1 and his wife were the parents of the infant who had recently died, and whose funeral was shortly to take place, so the enumerators were reluctant to press anyone who was not feeling like being questioned. In addition, person l's wife and her sisters are from community C. People from community A and its region characterise women from there as excessively shy and retiring, and this proved to be the case.

While we were at this house we saw the community E visitors departing in their vehicle from the dwelling which was to be our next port of call. We went there nevertheless, and one additional person was enumerated. He had returned from community B on the eve of census day. Our final visit was to a dwelling where the 'person 1' had not been enumerated, 
and there we also found his father, who was an as yet unenumerated 'person 1 ' for another dwelling. They had their SIPFs filled in rather hastily because the plane bearing the local candidate had just landed, and both men were anxious to get to the meeting.

The enumerators had been continuing to return the finished forms in their envelopes to the school 'office'. Most of the envelopes were there by this time. E4 and I now went there, and $\mathrm{E} 4$ began a second cross-checking session. Once the local candidate had departed we were joined by E1. E4 began by checking the SIHFs against the SIPFs once again. She noticed that one of the community $\mathrm{D}$ visitors had been enumerated twice at two different dwellings, and eliminated one of the forms. She also noticed that two community $\mathrm{C}$ visitors had still evaded enumeration, and marked them down for chasing. We already knew that all but one of the community E visitors had escaped being enumerated, but at least they were on the SIHF for the dwelling where they had been staying.

The envelope for that dwelling had now been returned, and it was discovered at this point that none of the SIPFs for the dwelling had in fact been fully filled in. The envelope for the dwelling was marked 'not complete', and it was subsequently visited again by E4 and E1.

As each SIHF and its attached SIPFs were checked, El and E4 filled in missing details on any partially completed forms that they found, including those for the community $\mathrm{E}$ visitors. They only filled in information that they were reasonably certain of. They were also checking for incorrectly filled forms (for example if people who were pensioners had also been put down as being in work). As each SIHF and its SIPFs were completed, they were placed in their envelope and it was marked as 'complete'. At this stage they did not fill in the summary on the second page of the SIHF. This was presumably done back at community B, when El went through the forms with the CFO.

My systematic observation of the enumeration ceased at this point. I have described the process in some detail in order to convey the context in which the enumerators were operating and their strategies for achieving the best possible result, as they perceived it, in the circumstances.

\section{The enumeration: a preliminary evaluation}

There is no doubt that the majority of the enumerators had taken on board the training that they had been given, were concerned to do the job well, and applied considerable ingenuity, flexibility and dedication to their task. It could also be said that, as far as enumeration scenarios in Indigenous communities go, this was a good one. This was a discrete small-scale community, and the ratio of enumerators to dwellings was almost 1 to 2. Moreover, the enumerators knew the community (and the comings and goings of its members) extremely well. Most of the people they were interviewing were close kin, and willing to cooperate.

There were, however, possible instances of double counting and of omission. These will be discussed in a later section. It is notable, too, that it took six enumerators over two days to enumerate the inhabitants of 13 dwellings. The reasons for this will become clear in the discussion of the interviews that follows. 


\section{The interviews}

While the enumerators were filling in the SIHFs before the enumeration proper, E1 remarked to me: 'It's a bit rude in [the local Indigenous] way of thinking to ask these [white people's] questions. We have to be careful about asking them.' He was to reiterate this sentiment more that once during the enumeration, and it clearly influenced the conduct of the interviews. The second major influence was the sheer size of the SIPF, and the time that it took to administer. Many of the strategies adopted could be interpreted as streamlining devices.

\section{Conducting the interviews}

During the day, most people sit outside when they are at home, so the enumerators simply walked up to each dwelling and announced to the assembled company that they were here to fill in the census. Most people already knew what they were doing, and very few raised any kind of objection, or asked for further information about the census. People who evinced shyness or reluctance (these were mainly youths or young adults of both sexes) were cajoled by their assembled relatives into cooperating. Here, the fact that the enumerators were well known to everyone worked to their advantage, and to the advantage of the enumeration process. People largely took it on trust that the census was a good thing, and saw their cooperation in personalised terms: they were helping their enumerator kin to do their job properly.

Everybody found the process of the interview a bit strange: they were Indigenous actors in a non-Indigenous scenario. Although everyone would normally speak to one another in the local language, the enumerators initially asked the questions in English, and the respondents replied likewise. However, if the meaning of a question was unclear, or the answer not straightforward, people usually switched to the local language for the ensuing discussion. The enumerators were asking kinds of questions that local people rarely ask one another, either because both parties already know the answer (name, sex, kinship relationships, marriage status, place of residence, origin and ancestry), or because they are about matters that are not of central concern (age, level of education, source of income, nature of paid work, hours worked). Humour was the main device used by both the enumerators and the interviewees to reduce the awkwardness of the occasion. There were many jocular false answers, and jokes at the expense of white people for wanting to know these things.

On the first day, E1 and E6 quickly settled into a standardised routine, that varied only slightly according to circumstance. Each person at the dwelling who was on the SIHF was asked to come and sit in turn with the enumerators. El asked the questions, while E6 filled in the form. In general, El also supplied the answers, verbally, to the questions for which he thought he knew the answers, and on occasion the interviewee would correct him, or a discussion would ensue before the question was finally answered. He directly questioned the interviewee only when he was uncertain of the answer.

Once everyone who was present had been interviewed, the household in general was asked about those who were absent. If a person was somewhere in the general area, but not 
actually at home, they were kept as candidates for SIPFs and noted down (mentally) for a later visit. In some cases it was discovered that people who had been marked as 'no' on the SIHF, because the enumerators had thought they were away, were in fact in the community. Their status was changed to 'yes' on the SIHF, and if they were actually present their SIPF was done. If a person who had been marked as 'yes' was actually away (at community B for example), their status on the SIHF was changed to 'no'. Significantly, the enumerators did not ask if there was anyone else who should be on the SIHF, and no one at the dwellings volunteered extra names, at least not in the cases I observed. Thus, if the enumerators had missed off any 'usual residents' when they compiled the SIHFs, the chances were that those people would be missed, unless they were actually present at the time of the interviews.

If there was anyone present at a dwelling who was on the SIHF of another dwelling, the enumerators also took the opportunity to do a SIPF for them, if they had not already been interviewed, on the principle of 'a bird in the hand'. This was a potential source of error: SIPFs could have got into the wrong envelopes, and the possibility of double counting also arose. Such errors did occasionally occur, but, as we have seen, they were picked up and corrected during the checking sessions at the school.

The interviewers were clearly committed to completing every SIPF in the presence of the interviewee. But had they asked everyone to respond to each question, the sessions would have dragged on interminably. In most cases their solution to this problem speeded up the interviews while not seriously compromising the quality of the data. El had a clear idea about which questions required answers from the interviewees and which questions he knew the answers to. Because the forms were filled out in the presence of the interviewee, that person had the opportunity to correct El if he got something wrong. That certain categories of people were less likely to do so was a possible source of bias: men and senior women were more likely to interject than were children and young women. Every interview took place within earshot of other household members, and there were often interjections from them in such cases. ${ }^{4}$ It could be argued, then, that the SIPFs of young women and children reflected less of their own knowledge about themselves and more of the opinions of the enumerator and more senior family members.

\section{Adapting to circumstance}

The general atmosphere of cooperation was weakened or broke down with two kinds of respondents: visitors from other communities and women from community $\mathrm{C}$ families, whether they were visitors or 'usual residents'. Although all visitors were kin to someone in the community, they did not necessarily know the enumerators very well. The community D visitors were cooperative when 'caught', but elusive: hunting and fishing were much higher on their list of priorities than filling in the census. The community $\mathrm{E}$ visitors, as we have seen, showed no desire to cooperate: the one who was 'caught' at his brother's house at first tried to evade the process ('We're only passing through, we don't live here'), but eventually gave in to pressure from the enumerators and his brother's family. 
For the community $\mathrm{C}$ women, especially the younger ones, the whole process was just too culturally inappropriate. They refused to answer out loud, retreated physically into the dwelling, or refused to come out to be interviewed. The enumerators adapted their interview strategy accordingly. Only female enumerators attempted to conduct these interviews, and they took place inside the house, or off to one side, in lowered voices. When all else failed the forms for the women were filled in later by the enumerators on the basis of their knowledge of the individuals concerned.

Other circumstances sometimes forced variations on the theme. One of El's MMBD (the sister of his actual MMBD, or 'mother-in-law') lives at one dwelling. In local society a FZDC ('son-in-law') and the women he calls MMBD, whether actual or classificatory, must avoid physical proximity and eye contact, and may only converse indirectly through an intermediary. The fact of working in pairs, as the CFO had correctly predicted, rendered this unproblematic. The CFO was also correct in his estimation that it was best to leave the handling of such situations to the enumerators themselves: avoidance behaviour is an everyday part of local life, and there are strategies already in place to accommodate it. It is not uncommon for a MMBD and her male FZDC to be members of the same household, since elderly mothers often live with one of their daughters. El's MMBD simply sat where she was. El had positioned himself at some distance from her and out of her direct line of sight, and E6 had sat down between the two of them. Interestingly, E1 and E6 still maintained their roles. El asked the questions in a quiet voice. E6 relayed the question to El's MMBD, El then answered the question (or the MMBD provided the answer herself), the answer was relayed by E6, and then E6 wrote the answer down if there was no dissent from either of the other two parties. El was unable to ask Q. 2 and Q. 4-6 (the questions on sex, kinship, and marriage), because a FZDC may not speak about, or hear anyone else speak about such matters in regard to his MMBD. E6 asked these questions herself, in a whisper, or simply wrote the answer down without asking. When it came to Q. 39, El tried to get $\mathrm{E} 6$ to ask it, but she was hesitant. So he asked the question quietly and she then repeated it word for word to the MMBD.

Although the enumerators tried always to do one SIPF at a time, there were times when they departed (or were forced to depart) from this principle. In the case of small children, where it was a parent or another relative who was helping with the SIPF, the enumerators often took one form each and worked on them simultaneously. This was not because children were considered less important, but rather because the enumerators quickly realised that filling in a form for a person under 15 years of age was more straightforward since several questions did not apply to them.

At two of the dwellings I visited, the enumerators were compelled to fill in more than one adult form at a time, or even to hand over the SIPF to the interviewee and allow them to fill it in for themselves. This was because the interviewees were about to go off hunting or fishing, and were anxious to be on their way. In one case the interviewees were some of the community D visitors, and in the other they were a group of local young men. The enumerators judged (almost certainly correctly), that people would vote with their feet if the interview process took too long, and so they resorted to this procedure. These SIPFs 
were subsequently reviewed during the checking sessions, and in some cases added to or amended in the light of the enumerators' personal knowledge of the interviewees.

I now consider briefly the responses to each of the questions on the SIPF, roughly in the order in which they appear on the form. The full versions of the questions on the form are found in Appendix C.

\section{Basic details (Q.1-3)}

Because the SIHFs had been filled in previously, the interview always began at Q. 1 of the SIPF. The enumerators did not follow the instruction to copy the answers to Q. 1-4 from the SIHF, but instead used Q. 1 and Q. 2 as a joking introduction. It is noteworthy that Q. 1, Q. 3, and Q. 4 are posed as direct questions on the form, which seems to contradict the instruction at the top of the form, but another factor that might have been significant here is that the enumerators considered it no more peculiar to ask these questions than any of the others. ${ }^{5}$

In Q. 1 (What is your name?), people's first names were sometimes spelled differently from how they appeared on the SIHF. One or two people appear under one name on the SIHF, and another on the SIPF. Everyone has several names, and the name by which they are referred to can change over time, for example on the death of someone who shares the name that is in current use. In one or two cases, interviewees said that their 'registered' name should be put on the SIPF, even if it was not the name they were currently addressed by.

Real difficulties began at Q. 3 (How old are you?): almost no one knew how old they were. Where they did know their year of birth they calculated their age with reference only to the year, not their actual date of birth. ${ }^{6}$ Quite often, the age recorded on the SIPF was different from the guesstimate that had been entered by the enumerators on the SIHF.

\section{Kinship (Q.4 and Q.5)}

The responses to Q. 4 (How are you related to Person 1 (Head of house)?) will be discussed in detail in a later section. The enumerators tried very hard to follow instructions, used English kinship terms themselves, and encouraged the interviewees to do so as well. The results will be uninterpretable. Q. 5 (Are you more closely related to anyone else in the house?) was quickly abandoned, at least in the interviews that I observed, for reasons that will become clear.

\section{Marriage (Q.6)}

The question (Are you married?) posed no problems to the enumerators or the interviewees. ${ }^{7}$ However the data collected at community A may cause some puzzlement to the sharp-eyed analyst. Two dwellings contain a female person 1 who describes herself as married, but no evidence of a cohabiting spouse in either case. Why do these women describe themselves as married, rather than as widowed, separated or divorced? The reason is that local Indigenous marriages are often polygamous: it is not at all uncommon for a man to have more than one wife (and often those wives are sisters). It has become common 
nowadays for a man to live with only one of his wives, and for the other wives to occupy one or more separate dwellings. In local terms this does not constitute either separation or divorce, if the relationship between the two parties remains amicable. In both the cases mentioned here, the husband lived in a nearby dwelling with another of his wives.

\section{Residence (Q.7-9)}

The 'place' questions also caused few problems for the enumerators and the interviewees, but the data almost certainly do not reflect what the census was after. 'Place', which is not further defined, was interpreted to mean 'community' rather than 'dwelling'. Moreover, people identify closely with the community as their home, even though they are at times highly mobile, and a 'yes' answer to Q. 7 (Do you live at this place most of the time?) reflects that identity rather than a computation about which community the person actually lives at 'most of the time'.

The instruction to give a street number, street name, suburb, and postcode if the answer to Q. 7 was 'no', as in the case of visitors, caused some hilarity. No one thinks in these terms. Although the community does have street names they are never used as a point of reference. Mail is not delivered house to house in this community. It does not have a street directory. People think in terms of ' $\mathrm{X}$ 's house', or 'the new house', or 'the blue house' (see Musharbash 2001: 4 for similar observations about Yuendumu). This is generally true of all communities in the region, even the larger settlements.

The ambiguity of the word 'place' did surface with respect to visitors, because the dwelling at which they were enumerated tended to be the 'place' at which they usually stayed when visiting the community. The use of the verb 'live' (as opposed to 'stay') was not enough of a trigger to automatically generate the correct response. However, after discussion, the meaning of place as 'community' took precedence, and the home communities of visitors were put down as their usual place of residence. Little attempt was made to think seriously about where anyone was actually living one and five years ago (Q. 8 and Q. 9). The default assumption was that the answer was the same as Q. 7, that is the community with which the person identifies.

This group of questions was invariably answered hastily and in a formulaic way, for three reasons. One derives from local Indigenous culture, in which place has very different connotations from those it has in the mainstream, and in which years, as a unit of measurement, have little significance. The two other reasons concern the design of the SIPF questionnaire. Because the questionnaire took so long to administer, the enumerators tended to supply, or readily accept formulaic answers to, questions that appeared to have self-evident answers, or which appeared, in local terms, to be unimportant, or even absurd. For this particular group of questions this impulse was compounded by the design of the questions themselves. There is something very offputting about being asked to provide a complete address, three times in a row, when one's dwelling does not have that kind of address, or, even if it does, is never thought of in those terms. 


\section{Origin and ancestry (Q. 10-13)}

These questions appeared at first sight to cause no problems at this community, where everyone is unambiguously of Aboriginal 'origin' (Q. 10) and 'ancestry' (Q. 13). A distinction between the two was also discerned-but it is not the distinction that the questions are aiming for. The details of the small print in Q. 13 (What is your ancestry?) draw on an implicit distinction between 'Indigenous', 'ethnic' and 'unmarked' (that is, Anglo-Celtic). These are not 'natural' categorisations, but ones embedded in the culture of mainstream Australia. Local Indigenous people do not categorise people in the same way. Moreover the content of these two questions is very problematic: neither says explicitly what information is really being sought.

I take Q. 10 to be a question concerning cultural identity (although it is not expressed overtly as such), and Q. 13 to be a question about biological (or 'ethnic' origins). The presence of the word 'ancestry' in Q. 13 led local people to a different interpretation. Ancestry was glossed by the enumerators as [sacred ancestral inheritance]. ${ }^{8}$ Thus Q. 10 was interpreted more as an enquiry about ethnic origins (or biology pure and simple) and Q. 13 as a more complex enquiry about spiritual (or cultural plus biological) identity and origins. The 'right' responses were obtained, but for the wrong reasons.

The small print in Q. 13, which provided a clue as to the intent of the question, was noticed and often read out by the enumerators, and jokes were made about people's ancestry. The tendency to treat the small print as a joke in this question was encouraged by the examples given for possible ancestries (Vietnamese, Hmong, Dutch, Kurdish, Australian South Sea Islander, Maori, Lebanese). Most are improbable ancestries for local people of mixed descent. Because of this the examples given were not sufficient to override the interpretation of 'ancestry' as [sacred ancestral inheritance].

Q. 11 and Q. 12 (Was your father/mother born in Australia?) were generally treated humorously, because the answer to both was so self-evidently 'yes' in all cases.

\section{Language (Q.14 and Q.15)}

The responses to Q. 14 (Do you speak an Aboriginal or Torres Strait Islander language at home?) were an accurate reflection of reality, in that everyone said they spoke an Aboriginal language at home. This is certainly true. For people who were from other linguistic regions, the 'language' name given tended to be a general one, and to correspond to what a linguist would classify as a language.

For local language speakers (the majority in this community), a much more complex picture emerged. The local Indigenous language is a language in the linguistic sense: it is a group of mutually intelligible dialects. But local people (and this includes the enumerators) rarely use the term that has been coined to designate the language. They commonly distinguish 'language' at two levels. They distinguish groups of dialects on the basis of their forms for the word 'this', and/or distinguish 'language' at the level of landowning group. Sometimes the labels are used separately, sometimes together. To the uninitiated, the census data would thus indicate that many different 'languages' are spoken in this community, 
whereas in reality most of the 'languages' identified are variants of one single language. Moreover, the same variant may be recorded under three different labels: 'this', 'landowning group' or 'this + landowning group'.

Q. 15 (How well do you speak English?) was answered with a high degree of accuracy, although there was some debate about whether the phrase [a little bit, somewhat] should be translated as 'well' or 'not well'. People are in general able to assess objectively their level of competence in English. ${ }^{9}$ Adults tended to assess their own level of competence, and the enumerators accepted their self-assessment. For children, however, the enumerators adopted a formulaic approach: infants and pre-school children were said to speak English 'not at all', and schoolchildren were said to speak it 'not well', 'because they're just learning'. In one case a man wanted to put that his small grandson spoke English well, but he was overruled by the enumerators.

\section{Religion (Q. 16)}

Q. 16 (What is your religion?) generated much debate; people wanted to mark more than one box. Many if not most local people are 'bi-religious'. As one interviewee put it: 'My beliefs are traditional, but my religion is [Christian denomination]'. The reasons for this lie partly in the mission history of the region, for by and large the founders of the missions in this area were respectful of the local religious belief system and did not attempt its wholesale repression, and partly in the nature of the local Indigenous metaphysic, which is incorporating and syncretic rather than exclusive. One might say that for local people their traditional religion is their Old Testament, and Christianity is their New Testament. Each has its place and function in the contemporary worldview.

There is no explicit indication that it is permissible to mark two boxes for this question. El's solution was to mark only 'Traditional Beliefs', often declaring as he did so, '[Indigenous] comes before [white man], so we'll put Traditional Beliefs'. Most interviewees agreed to this. The other enumerators sometimes marked both [Christian denomination] and 'Traditional Beliefs', and sometimes only one or the other, depending presumably on what the interviewee's response was.

\section{Computers and the Internet (Q.17 and Q.18)}

There are no computers in the community, so not surprisingly everyone responded 'no' to these questions. This is not to say that no one knows how to use a computer. At least one person put a computer course down at Q. 23, and the teachers and HA employees in the community all use computers to some degree in their work. The base school at community B makes use of the Internet, and the community teachers may well have some experience of using it.

\section{Education (Q. 19-22)}

Q. 19 (Do you go to school, TAFE or university?) and Q. 20 (What type of school or place of education do you go to?) caused no problems, and were answered accurately. One person was in the middle of a teacher-training course of some kind, but it was difficult to decide 
which box to mark in Q. 20 because it was an in-house course at the homelands school headquarters in community B.

Q. 21 (Are you 15 years of age or more?) was found to be odd, because people had already said their age earlier. The enumerators finally recognised it for what it is - a cue to go to the end of the questionnaire if the interviewee is under 15 years of age.

Nearly everyone had difficulty with Q. 22 (What is the highest level of primary or secondary school you have completed?), including those enumerators who are teachers. The prompt 'Year 8 or below' had no salience for them: had the term 'primary' been used there would have been no problem. Very few local people have more than primary education, and the outstation school has no post-primary section. Even most of the teachers went no further within the school system as such. For those people who had been educated in 'mission time' this question was even more difficult to answer, and it was sometimes left blank.

\section{Further education (Q.23-27)}

The vast majority of interviewees answered 'no' to Q. 23 (Have you finished a trade certificate/apprenticeship, TAFE course or university course since leaving school?). For those few who answered yes, the box that was always marked was 'Yes, other course'. This was a faut de mieux response, because people did not know whether the courses they had attended were or were not a 'trade certificate/apprenticeship'. Q. 24 (What is the name of that course?) caused some problems because what is really being asked for is the name of the qualification rather than of the course, but the wording is misleading. Most of the courses people had done were not certificate, degree or diploma courses. Under 'Full name of course' people invariably put a descriptive title rather the name of the qualification, so that the information supplied there tended to overlap with or be the same as that supplied for Q. 25 (What did you study?). Q. 26 (What was the name of the place you studied at?) caused difficulty for some because their courses had not taken place at a particular institution. For Q. 27 (In which year did you finish that course?), most people were able to produce the certificate that showed when the course finished.

\section{Money each fortnight (Q.28)}

HA policy is that people without other regular sources of income (e.g. pensions, or 'real' jobs) who live at outstations are paid for 20 hours of CDEP work per week. This was the case for the majority of adults in community A. For these people, the amount recorded at Q. 28 (How much money do you get each fortnight before tax?) was always the same, that is \$320-\$399 per fortnight. The enumerator rather than the interviewee supplied the answer. If people were on a pension of some kind, the enumerator also filled in the amount. I did not ask the enumerators how they knew the correct answers to this question: clearly they had either been instructed on the right figures to enter, or had thought to find them out prior to the enumeration. ${ }^{10}$

No attempt was made to compute other sources of income, for example from art production or royalties, although several members of the community derive income from one or both. 
I suspect that this is because, in comparison to the known income from CDEP and pensions, the enumerators felt it would be too hard to elicit this information. Income from these other sources does not come in a steady stream, and it would have been very difficult to work out a fortnightly amount. The subject was never raised, either by the enumerators or by the interviewees.

\section{Did you have a paid job last week? (Q.29)}

For people on CDEP, the answers given to this question were correct - but for the wrong reason. The question was interpreted as 'Did you have a pay last week?' Fortunately, the previous week had in fact been a CDEP pay week. This question needs to be rephrased if it is to be asked next time. The word 'worked' or 'work' needs to find its way into the large print in the main question. ${ }^{11}$ The local interpretation of the question suggests that for local people, as far as CDEP is concerned, the word 'pay' is more salient than the word 'job'.

\section{Job description and content (Q.30 and Q.31)}

Q. 30 (What job did you do last week?) and Q. 31 (What things did you do in that job last week?) caused difficulties initially until the enumerators worked out what the difference was. A standardised response emerged: Q. 30 was answered with 'community service' and Q. 31 with what the actual 'work' consisted of. 'Jobs' included 'community leader' and 'home management', and there were a lot of 'rubbish collectors'. The enumerators and interviewees were clearly responding to the prompt in the question, which lists only 'jobs' that would be considered as such in mainstream terms. No-one put down 'making art works', or 'hunting' or 'fishing', although many people on CDEP spend more time in those kinds of activities than in those contained in the prompt to the question. For example, after discussion with the enumerators, one person answered Q. 30 with 'community work', and Q. 31 with 'community leader'. His brother from community E remarked: 'you should put artist' - an entirely reasonable suggestion since person 1 is one of the best known artists from the region, whose works are found in national and international collections. The suggestion was not taken up.

\section{Who is the employer? (Q. 32-34)}

The wording of Q. 32 (Who did you work for last week?) focused people on the local community, rather than on the HA which administers the CDEP program. The word 'for' in this question has more than one possible interpretation. It can mean for whose benefit did you work? Or alternatively it can mean 'who did you work for in your capacity as an employee? The use of 'who' forces the first interpretation: the community, which consists of a collection of known individuals, is a more salient candidate for 'who' than is an organisation based at community B. The small print did not help in this case, because the word 'community' cued the name of the community rather than the over-arching organisation.

Q. 33 (What is your workplace address?) caused the same difficulty as other questions that asked for addresses. There are only three official 'workplaces' in the communitythe school, the community shop, and the clinic (which did not function on a regular basis 
at the time). Like dwellings, these workplaces are not thought of in terms of their address. These questions were clearly not formulated with remote communities in mind.

Q. 34 (What work does your employer do?) focused people's attention on the HA, because of the presence of the distancing word 'employer'. People do not regard their own community in those terms. The counter-intuitive instruction in small print to write 'community council' was overlooked, except by one community D visitor. Instead, the enumerators devised a formula to describe the activities of the HA (variations on 'provides community programs').

\section{Hours of work (Q.35)}

The answers provided to this question (How many hours did you work last week?) were formulaic. If a person was on 20 hours of CDEP the answer was ' 20 '; if they were in fulltime CDEP the answer was '40'. The enumerators supplied the answer, and no one disagreed. No attempt was made to compute the actual number of hours worked, and it would not have been possible to do so: nobody wears a watch or keeps track of time by the hour in the outstation context.

\section{How do you get to work? (Q.36)}

This question provided another opportunity for humorous responses, because everyone gets to work on foot. Levity was not unwelcome at this stage in the proceedings!

\section{Looking for work (Q.37 and Q.38)}

Q. 37 (Did you look for work at any time in the last four weeks?) and Q. 38 (If you had found a job, could you have started work last week?) were both answered in the negative by everybody, including those on CDEP. A common comment by the latter in reply to Q. 38 was 'no, because already got a job'. By this stage the interviewees had clearly realised that CDEP was being treated on the SIPF as payment for 'work', and were happy to fall in with this definition.

\section{Consent (Q.39) and Declaration (Q.40)}

The enumerators had been carefully schooled to ask Q. 39 (see Appendix C) in the local language; they had evolved a formula for it during their training session and had practiced asking each other. The CFO's concern, transmitted to them, was about people being uneasy about hearing the names of dead people. The question as asked in the local language focused on the form being put away in a safe place in Canberra for a long time, and being brought out [when you are a old person, so that you or your grandchildren can see it, and see your name there]. The period of 99 years was interpreted as [a long time], but the precise period of time was not really understood. Put in this way, consent caused no problems for local people, who recycle names from grandparent to grandchild: 'it's OK, because your [(Z)DC] will be using that name by then'. Everyone answered 'yes', but it is arguable that they were responding to a different question from that actually being asked in Q. 39. 
Q. 40 asks for the interviewer to declare that they have explained the requirements of Q. 39 to the person interviewed, and that they have correctly recorded the person's views at Q. 39. However, the interviewers did not at first read the small print, and the early forms were signed by the interviewee, at the request of the interviewer. El noticed the small print at some point during the first day, and thereafter the interviewers signed the forms.

\section{A complete enumeration?}

Two overarching factors - the legendary mobility of Aboriginal people coupled with the logistical necessity of the rolling census under the present arrangements for enumerating Indigenous populations in remote regions - militate against the achievement of a 'perfect' enumeration. In terms of coverage, the enumeration at community A was as good as it could be: as far as I could ascertain, there was no systematic under-counting or double counting in the community itself. There were isolated cases of each, and these will be discussed below because they may point to potentially systematic sources of error. However, it was not possible to gather systematic data on the enumeration (or non-enumeration) of absent 'usual residents', and it is possible that, as noted earlier, up to 50 per cent of 'usual residents' were not in the community during the enumeration.

The success of the enumeration flowed from several sources. The community is relatively small and its 'usual residents' have a strong sense of belonging to it. There was little difficulty in defining who counted as a 'usual resident', whether absent or present, and who was a 'visitor', although local definitions of these terms do not coincide absolutely with those envisaged by the designers of the census (this point is discussed further below). The local knowledge of the enumerators, who were well and appropriately recruited, was also a very significant factor, in two ways. Their detailed knowledge of the community ensured that coverage was as complete as humanly possible, and their membership of the community, as kin to the interviewees, ensured the community's cooperation (on the whole). Finally, the training that the enumerators received, although curtailed, was quite evidently effective. They knew in principle what they had to achieve, and had been given the necessary tools to carry out the task successfully.

\section{The 'ceremony effect'}

At one dwelling the SIHF listed 12 'usual residents', five of whom had been at community B staying with a relative at the time of the enumeration there. They were listed on the SIHF of that relative's dwelling as visitors, and enumerated at community B. ${ }^{12}$ These people were still at community B when community A was enumerated, and so did not have SIPFs done at community A. A sixth 'usual resident' of the dwelling (person 10) had gone to community B to join the other five, and then left for a funeral ceremony elsewhere before the enumeration at community B. He was, nevertheless, enumerated at community B in absentia, because he was expected to return there to join his other 'visitor' relatives. However, he returned directly to community A and was enumerated there, as a 'usual resident'. He was not asked if he had been enumerated elsewhere, but even if he had been 
asked he would not have known that he had already been counted at community B with the other five 'visitors' from community A.

Although this was an isolated case of double counting, it resulted from factors endemic to the context of the enumeration of the region. Other cases of the kind almost certainly occurred. The funeral mentioned above attracted many people from the region, who were then, of course, absent from their usual places of residence - or from the place where they were recognised as 'visitors' - for the duration. It would have been quite inappropriate to conduct the enumeration during the ceremony, and so this was not attempted: the community where it took place was enumerated after the ceremony was over. The enumeration at community B occurred while the ceremony was on, and anyone who was known to be at the ceremony, who would normally have been at community B (as a resident or as a visitor), was enumerated at there 'as if' they were there. Thus anyone who, like person 10, subsequently left the ceremony and went to an as yet unenumerated outstation instead of returning to community B was a potential candidate for double counting. There appears to be no perfect solution to this conundrum. Had the people attending the ceremony not been enumerated in absentia, those who returned to community B would not have been enumerated at all, because the count at community B had been completed before the ceremony ended.

Funeral ceremonies are, alas, all too common in the region. During the two months I spent at community A in 2001 there were two funerals in the community itself. Preparations for two other major funerals at nearby outstations were under way when I left. Funerals and other types of ceremony are a major cause of unpredictable short-term population mobility in the region: some people are almost continuously on the move from one ceremony to another, and some ceremonies attract large numbers of people for short periods from across the region. No dwelling-based enumeration strategy can ever be devised that will fully counteract the effects of this specific type of intra-regional mobility, because it would never be appropriate to conduct the census enumeration at a community during a ceremony. The practice of enumerating ceremonial attendees as if they were in their usual place of residence is a departure from the principle of enumeration in situ, but it is better than failing to enumerate them at all.

\section{The effect of other kinds of short-term mobility}

Person 1 from a particular dwelling in community A was at community A when the settlement B enumeration took place. However, she subsequently went to settlement B for a short visit, and was still there when community A was enumerated. She was therefore not enumerated either at community A or at settlement B. Note, however, that although no SIPF was done for her she did appear as person 1 on the SIHF for her dwelling at community A.

I suspect that this was not the only case of this kind in the region, despite the best efforts of the CFO and the CCs and enumerators. The residents of an entire dwelling at community A would have fallen through this same crack had they not serendipitously returned to 
the community while the enumeration was in progress. Cases of double counting (other than ones of the 'ceremony effect' type detailed above), where someone happened to be present for the enumeration in two different places at two different times, might also have occurred, but this is less likely because 'visitors' were usually asked if they had already been enumerated elsewhere. However, at community A at least, 'usual residents' were not asked if they had been enumerated elsewhere as a visitor.

\section{Assessing the extent of under-enumeration and double counting}

It would be possible, in theory, to assess the extent of under-enumeration and double counting by comparing the SIHFs for the whole region (i.e. settlement B and its associated outstations), looking for people who were listed as 'usual residents' but were absent, and then searching to see if they appear as enumerated 'visitors' at some other community. It would also be possible to check whether 'visitors' in one place had also been counted at the place where they were 'usual residents'. But this could not be done efficiently without the help of the local enumerators. They alone would be able to narrow down the range of possible alternative locations for such individuals: people's short-term movements are never random, but are constrained by considerations of kinship and attachment to place. People might also be under different names on different SIHFs, or their name might be spelled differently. Again, only someone with local knowledge would be able to make correct cross-identifications in such cases.

It is important to note, however, that this type of cross-checking is only possible if:

- $\quad$ every dwelling in a region, including those which are temporarily vacant, has a SIHF on which all usual residents are listed, and on which all visitors present at the time of the enumeration are also listed;

- 'usual residents' are listed as either present or absent, and only have SIPFs filled out if they are present;

- all visitors who are listed on the SIHF also have a completed SIPF; and

- exceptions to the above are clearly defined and adhered to. Usual residents who are absent at the time of enumeration, but will not be enumerated in the place where they are, for example at a ceremony (or at a sports carnival—see Martin and Sanders, this volume), should be enumerated 'as if' they were present.

The count at community A approached this ideal, as did the count at settlement B and in the region generally.

A 'usual residence' count, where everyone was enumerated on a SIPF according to their usual place of residence, whether or not they were actually there at the time of the enumeration, would be an alternative, but less satisfactory, strategy. The quality of the data on the SIPFs would suffer, since many more SIPFs would be filled out in the absence of the individual concerned. Moreover, visitors who were actually present would not be enumerated, on the assumption that they were being enumerated at their usual residence, in absentia (see Sanders, this volume). Such a strategy is therefore also much more dependent on the robustness of the definition of 'usual resident'. 
The worst-case scenario would be one where these two strategies were mixed within a single region. This would result in a high incidence of both double counting and undercounting, and it would be well nigh impossible to cross-check the data.

\section{The role of the SIHF}

Whichever strategy is adopted, the SIHF is a crucial tool. Because it lists both absent usual residents and visitors, it provides a snapshot of the level of inter-community mobility, and it provides a means of checking for double counting and under-counting. However its usefulness is dependent upon two definitions: that of the 'dwelling' and that of 'usual resident'.

In small cohesive communities such as community A, the definition of 'usual resident' is unproblematic, although the local definition does not correspond to the ABS definition. For one thing, as we have seen, it is the community rather than the particular dwelling within it that people have in mind as the 'place' where they reside. The ABS definition of 'usual resident' is also based in the notion of calendar time, and this does not apply to the local definition, at least not in such an absolute sense. ${ }^{13}$ For example, some of the absent 'usual residents' of one dwelling at community A had been at community B more or less continuously for over a year, because one of their number was doing a year-long course at the local Health Centre. Nevertheless these people consider themselves, and are considered by others (including the enumerators at both $\mathrm{A}$ and $\mathrm{B}$ ) to be 'usual residents' of community A and 'visitors' at community B, because community A is the locus of their most significant personal and spiritual attachments, and is the place they intend to live in the long term.

However, even within this region, and more so in other areas of Australia, the notion of 'usual resident' has been, and most probably continues to be, problematic. If the census is viewed strictly as a snapshot view, the data contained on the SIHFs accurately reflect the general situation: Indigenous people are highly mobile, and at any one time many will be 'visitors' at places other than their 'usual residence'. But it would be unwise to use the census data as the starting point for a more fine-grained analysis of attachment to place and patterns of mobility.

\section{What constitutes a dwelling?}

The case of the absent tent-dwellers from the yard of one dwelling highlights the other definitional problem alluded to above. These people were, for the moment, 'visitors' at community A, on an extended visit to their daughter, but happened to be absent (at community B) at the time of the enumeration at community A. Because their tent was a 'nonhouse' with no occupants who were usual residents of the community it was not designated as a vacant dwelling, and so it had no SIHF. Nor was it counted as part of dwelling that it was pitched next to. It is highly unlikely that these people were enumerated on SIPFs elsewhere. It is also possible that they did not appear on a SIHF anywhere. They have a permanent dwelling at another outstation, but that dwelling was currently vacant. 
At the time of the enumeration, this happened to be the only tent in the community, but had the enumeration taken place in the following week, there would have been several more. Many 'usual residents' had returned by that time, and most houses in the community are too small to house their full complement of inhabitants comfortably. Until recently people got round this by sleeping on the veranda (if there was one), or out in the open. But tents have become very popular locally over the last two or three years, and are easily obtainable at affordable prices in the local town. They are now regularly used as extra bedrooms if a house becomes overcrowded - either temporarily (as when visitors arrive for ceremonies) or in the medium term, when the full complement of usual residents is present.

Functionally, these tents are extensions of a permanent dwelling, and their occupants are, more often than not, 'usual residents' of the dwelling and members of the dwelling's household. The difference is only in the eye of the non-Indigenous beholder, for whom a tent is a 'temporary dwelling' rather than an 'extra bedroom'. ${ }^{14}$

\section{Missing persons 1}

Had I not been present, a significant number of 'person 1s' at the community would not have been enumerated on a SIPF. According to the CFO this did not happen anywhere else in the region, but it is worthy of discussion because it highlights a particularly salient point of difference between local Indigenous and mainstream social structure and cultural values. I did not notice the systematic omission immediately, because the first two dwellings we visited on the first day did not result in complete enumerations. At the third dwelling, however, I noticed that no SIPF was completed for person 1 , in this case the oldest member of the community.

I asked the enumerators if they were going to do a SIPF for this man, thinking that they had just overlooked it because he was inside the house. To my surprise, they said that they did not think it was needed. I decided at this point that I would be doing everyone a favour if I temporarily abandoned my 'observer' status. (And besides I was intrigued: what could the reason be?) So I asked why. The answer was that it was not necessary for person 1 in each household to have a SIPF done, because their kinship relationship to everyone else in the household was already specified on the SIHF. Thus at this stage they were thinking of the SIHF as person l's SIPF.

What led them to this conclusion? The reasons must have been powerful, for they produced what might be called a culturally induced 'blind spot': they overrode the principles which had been inculcated during training - principles which the enumerators had obviously otherwise taken on board. And indeed it took more than one conversation to convince them that SIPFs were needed for these individuals.

There were several factors that conspired to produce this 'mistake'. Question 4 on the SIPF asks for information that has already been recorded on the SIHF. So indeed do Q. 1, Q. 2, and Q. 3-but with an important difference. For local people, the most salient question on the entire SIPF is Q. 4, because kinship is the central organising principle of their society. The misapprehension that person 1 does not need a SIPF is reinforced by the design of Q. 4 (see Appendix C). It asks in big bold letters how the person is related to person 1 . The little box for marking if the person is person 1 needed to have explicit instructions beside it, in lettering the same size as the main question. 
For the enumerators, Q. 4 simply did not apply to person 1. This fact overrode all else, and their view was reinforced by the design of the SIPF. If Q. 4 had been placed further down the SIPF, it would not have acted as a brake to further questioning of person 1; placing Q. 4 in such a prominent position carried the implication that the information it elicited was as significant to the author of the form (i.e. the ABS) as it is to local people, which is to say that, by comparison, the other information elicited by the SIPF is relatively unimportant.

As will be evident from the general thrust of this paper, the advantages of employing local enumerators in Indigenous communities far outweigh the disadvantages, and no criticism of the enumerators is implied here. But Indigenous enumerators are being asked to do something very difficult, to deploy the skills and knowledge that they have acquired as members of their community, while simultaneously assuming the position of temporary 'outsiders' - agents of the state as it were. The designers of the SIPF need to be more aware of this delicate balance. Kinship is not as important in the 'mainstream' society as it is for Indigenous people. It is certainly not so important that it renders other information irrelevant. If questions on family relationships are to be asked, they should be in a less prominent place; or they should be radically rethought. This issue receives further discussion in the next section.

\section{The 'household' and its structure}

Questions 4 and 5 on the SIPF attempt to elicit information about household structure using the idiom of kinship. All socialised human beings -including those raised in societies where the Anglo-Celtic system prevails - view their kinship system and its kinship terms as 'natural', because they are inculcated at such an early age. However, the kinship terminology of mainstream Anglo-Celtic Australia, like local Indigenous kinship terminology, forms an elaborate abstract system in which terms only have meaning in relation to the overall structure of the system. If two kinship systems differ markedly in their structure, it is not possible to simply translate the terms from one system to the other. The principles according to which the Anglo-Celtic system is constructed differ markedly from the principles underlying the local system. In the following discussion I hope to show conclusively that it is impossible to elicit information about one such system in terms of another, and that the data resulting from such an attempt are doomed to be uninterpretable.

\section{Kin terms: a comparison}

In the Anglo-Celtic system, the term cousin is used to refer to the children of a person's (ego's) father's sisters and brothers, and of their mother's sisters and brothers. In other words, the system merges under the term cousin all the children of ego's parent's siblings. Note also that the Anglo-Celtic term cousin is neutral with respect to sex. Anglo-Celts call the children of their own father and mother either brother or sister, depending on their sex. The local Indigenous system is completely different. Local people call the children of their mother's brother MBC and the children of their father's sister by a different term, FZC. A MBC may also simultaneously be a MMBDC, and the same term is applied to both categories of relative. Like cousin, these terms are neutral with respect to sex. Put another 
way, the system distinguishes two kinds of cross-cousins: matrilateral (MBC) and patrilateral (FZC). Local people call the children of their mother and her sisters and of their father and his brothers B if they are male and Z if they are female. In other words, in the local system siblings and parallel cousins are merged. Like the Anglo-Celtic terms for siblings, these too are differentiated by sex. Fig. 3.3 illustrates the differences between the two systems for the set of terms for siblings and cross and parallel cousins.

\section{Fig. 3.3 Siblings and cousins in the Anglo-Celtic and local Indigenous systems}

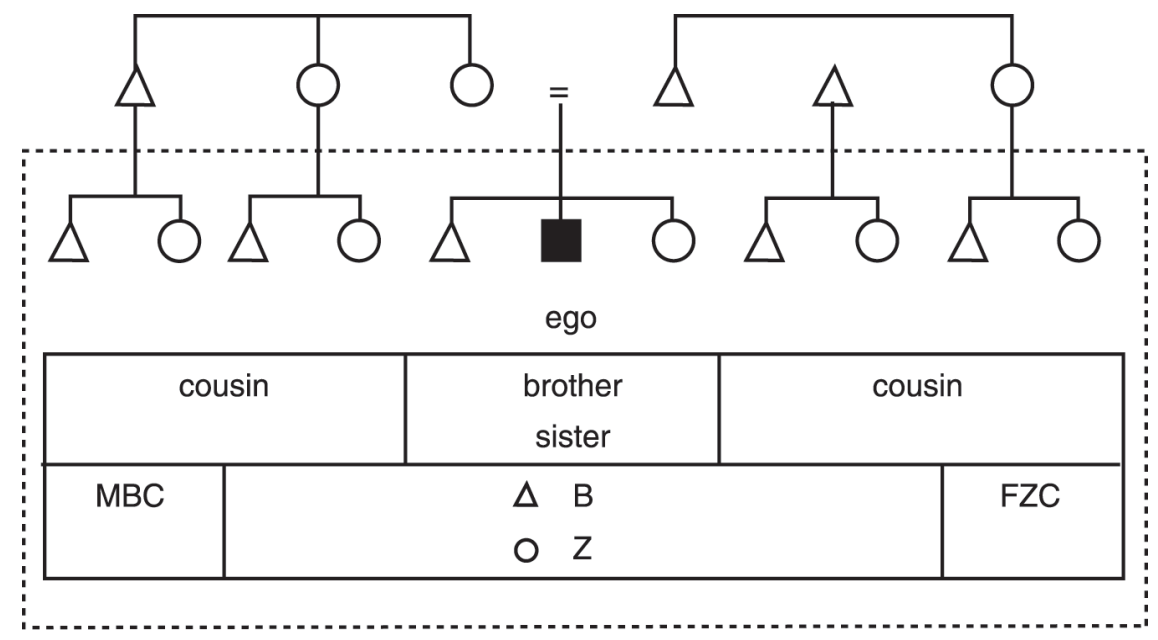

People raised in the Anglo-Celtic system think of son and daughter as 'natural' categories. Children are defined, as it were, with respect to their parents' marriage: both parents use the same terms for their offspring. The children of ego's brothers and sisters are merged under the term nephew for males and niece for females. The local Indigenous system operates according to a different set of principles, which appear just as 'natural' to local people. A woman calls her own children and those of her sisters ZC, and those of her brothers by a different term, BC. A man calls his own children and those of his brothers $\mathrm{BC}$, and those of his sisters $\mathrm{ZC}$. Children are here being defined not with respect to their parents' marriage, but with respect to their lineage: BC means 'child of my patriline' and ZC means 'child of my matriline'. These terms for children (as with Anglo-Celtic cousin), are not differentiated according to sex. Fig. 3.4 illustrates the differences between these sets of terms in the two systems. 
Fig. 3.4 Children in the Anglo-Celtic and local Indigenous systems

Male ego

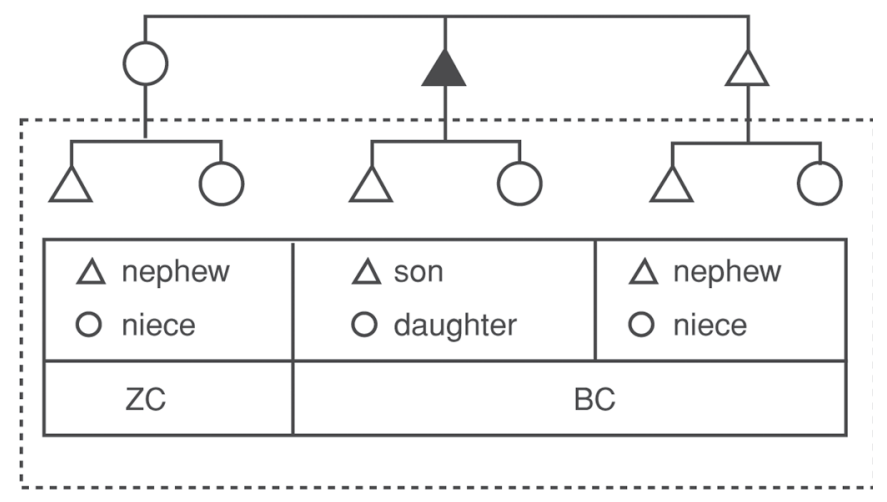

Female ego

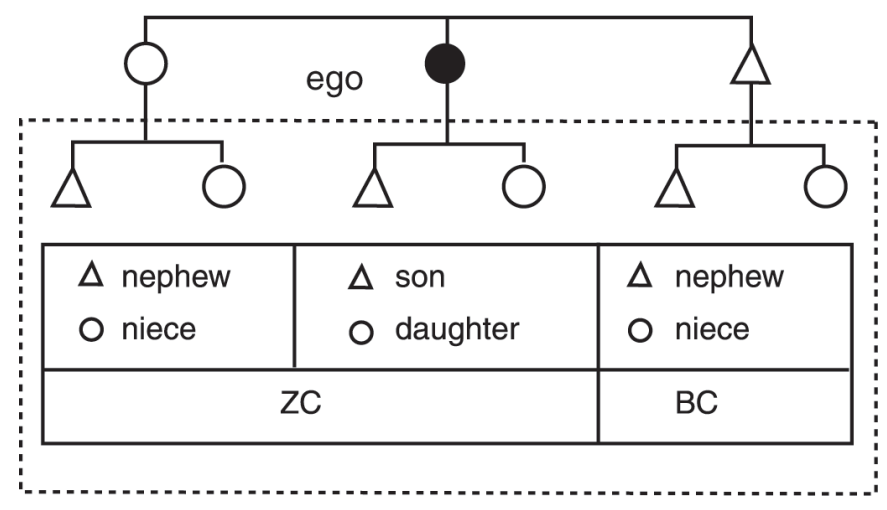

All kinship systems have terms that are 'classificatory' in the sense that they classify people together according to a set of underlying structural principles. The term cousin is probably the most classificatory of the Anglo-Celtic kinship terms (although uncle, aunt, grandparent, and the category in-law are quite complex as well). But the local Indigenous system applies more (and more abstract) principles of classification than does the Anglo-Celtic system. For example, males in the generation above ego in ego's patriline (including ego's own father) are F, and all females in the generation above ego in ego's mother's patriline (including ego's own mother) are M. But these terms have even wider application: they apply also to kin in generations other than the parental generation. 
Fig. 3.5 The Anglo-Celtic term mother and the local Indigenous term M compared

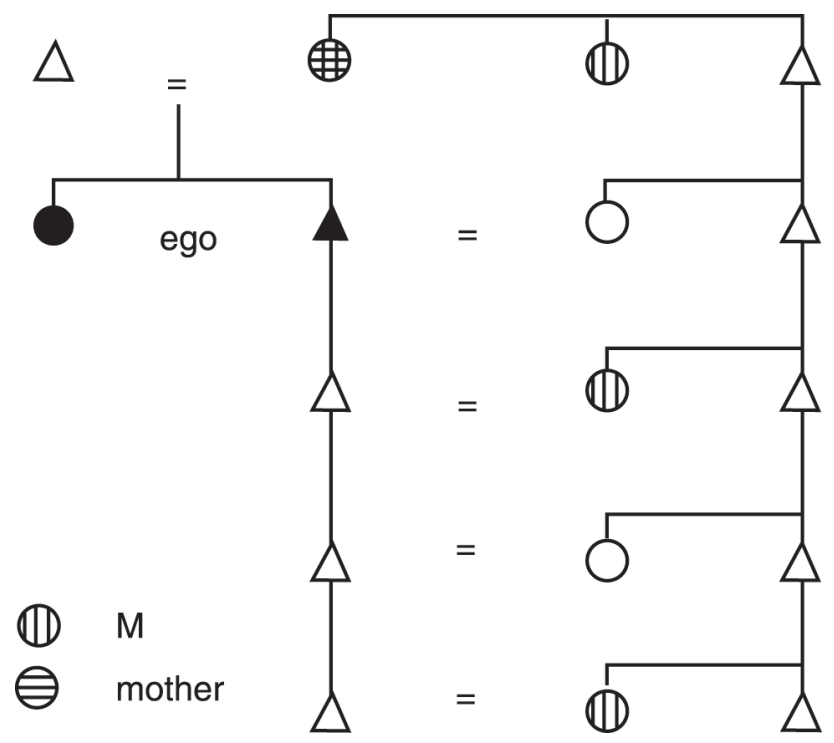

If one thinks of ego's own generation and the generations of their grandparents and grandchildren as 'even' and ego's children's, parents' and great grandchildren's generations as 'odd', the term M applies to any female member of ego's mother's patriline who is in an 'odd' descending generation with respect to ego (see Fig. 3.5). No M is any more or less of an $\mathrm{M}$ than any other, just as no cousin is any more or less of a cousin in the Anglo-Celtic system. ${ }^{15}$ People have been told that $\mathrm{M}$ means 'mother', and so that is how $\mathrm{M}$ was often translated by the enumerators, whether the person was, in Anglo-Celtic terms, a mother, a daughter-in-law, a nephew's wife, a great granddaughter-in law, or a brother's great granddaughter-in-law. The last two, significantly, are scarcely kin terms at all in the AngloCeltic system. Sometimes the enumerators, realising that some categories of $\mathrm{M}$ do not count as mother in the Anglo-Celtic system, attempted to substitute the 'correct' Anglo-Celtic term - with varying degrees of success, as we shall see in the case of one dwelling (see Fig. 3.7 and the accompanying discussion). None of the Anglo-Celtic terms for the kin comprising the 'nuclear family' are directly translatable into local Indigenous kinship terms. And vice versa: none of the core terms, let alone the non-core terms, of the local Indigenous system are directly translatable into Anglo-Celtic kinship terms. The AngloCeltic reader, who is probably suffering from 'kinship fatigue' at this point, should bear in mind the plight of the Indigenous enumerator, who is faced with exactly the same problem (seen from the other side), in a real-time interviewing situation.

The local Indigenous and Anglo-Celtic systems differ in another very important way. In the Anglo-Celtic system (as it operates today), people are rarely kin to one another before they get married. A marriage brings together, in a set of in-law relationships, two previously unrelated kindreds. Their only point of intersection is the married couple - the husband and wife - and the connection is then carried down into the couple's descendants. 
In the local Indigenous system, the preferred marriage is between people who are already in a kinship relationship: a man marries his (actual or classificatory) matrilateral crosscousin: his MBD. A woman thus marries her (actual or classificatory) FZS. Marriage in the Indigenous system does not create bonds of kinship: it reinforces and reaffirms already existing kin relationships. So a man's MBD may be his wife, but she is also a kind of cousin in the Anglo-Celtic system, and a man's male ZC (actual or classificatory sister's son) is his nephew in Anglo-Celtic terms, but may also in addition be his daughter's husband, or sonin-law. Thus it is perfectly possible for a woman with no daughters and an unmarried man to refer to each other as FZDC 'son-in-law' and MMBD 'mother-in-law' respectively, as happened on one SIHF and the related SIPFs.

The Indigenous kinship terminology encompasses categories of people on which the Anglo-Celtic system is silent. It distinguishes and covers seven patrilines that are related matrilineally through the marriage system. The Anglo-Celtic kinship terminology focuses on the individual and their direct ancestors and descendants, and merges patrilineal and matrilineal kin at every level. The system fades off very quickly into cousins and then non-kin as soon as it leaves the realm of ego's nuclear families of origin and procreation. In the Anglo-Celtic system there is no term for (Z)DDFZC, who is the person (or the sister of the person) who potentially marries your (Z)DD (daughters' daughter from a female point of view, and sister's daughter's daughter from a male point of view). El and I had several conversations about how such a person should be characterised in English. The option of classifying a (Z)DDFZC as a 'friend', or as 'unrelated', did not enter the frame.

For Q. 4 the enumerators were often successful in assigning the 'correct' term - in AngloCeltic terms - with core kin. In at least one case, a father's brother, who in local terms is another F ('father') was put down as 'uncle', and the use of the terms 'nephew' and 'niece' corresponded to Anglo-Celtic usage. The enumerators' own superficial knowledge of the Anglo-Celtic system and the training provided by the CFO thus had some effect. But it did not penetrate very far into the system.

It should now be clear that in the context of local Indigenous kinship, Q. 5 is unanswerable. Even if one is operating according to the Anglo-Celtic kinship system it is difficult to know how one might answer it. Who is closer to ego: father or mother? In a three-generation household, who is closer to ego: parent or child? Is the relationship to a spouse closer than to a child? Is the relationship to a sibling closer that to a child? What precisely is meant by 'closely related'? Is it a question about biology, or a question based on unexamined assumptions about what constitutes closeness in terms of a particular system of kinship? It is not surprising that this question was left blank on the majority of SIPFs. El commented at one point: 'this is a real [white man's] question', by which he meant that it made no sense in local Indigenous terms.

\section{Household composition}

Anglo-Celtic kinship, then, is not the ideal idiom for attempting to elucidate the structure of local Indigenous households. But what of the implicit model of the household that lies behind the census questions? The definition of the household given in the 2001 Census Dictionary (ABS 2001) allows for the possibility of more than one 'household' in a dwelling, 
but not for households whose membership is spread across more than one dwelling. Two major types of 'household' are identified: those whose members are 'related' (family-based households), and those whose members are 'unrelated' (group households).

In the ABS definition of the family, 'the basis of a family is formed by identifying the presence of either a couple relationship, lone parent-child relationship, or other blood relationship ... other related individuals (brothers, sisters, aunts, uncles) may be present in the household' (ABS 2001; emphasis added). Although the ABS does not use the term 'nuclear family' it is clear from the definition that this is what is meant by a 'family', since other 'related individuals' may be associated with it, but are not part of it. Daly and Smith provide a succinct account of how the ABS categorise the data obtained from 'multi-family' households: '[T]he nuclear family of parents and children is taken as the base around which all family types are constructed, and other families within the household are placed in relation to this "primary" family ... if there are more than three family types in a household, the adults in any additional families are "disbanded" as a family type, reclassified as related individuals, and assigned to the "primary" family" (2000: 12).

The model does not fit the Indigenous facts on the ground. Indigenous households 'who make common provision for food or other essentials' (ABS 2001) are often spread across more than one dwelling (for example in the case of a man and his co-wives, as discussed elsewhere in this paper). Moreover, previous ethnographic work on Indigenous household structures led Daly and Smith to conclude that: 'the nuclear family is not the most common residential form ... indigenous households in the 1990s were characterised by considerable compositional complexity, porous social boundaries and large size' (1999: 2). These generalisations continue to hold true for the households at community A in 2001.

Table 3.1 shows the 'usual residents' of dwelling $\mathrm{J}$ as they were listed on the SIHF for the dwelling. The local Indigenous kinship term by which person 1 actually addresses each person is given in the last column. Superficially, this looks like a four generation family, consisting of person 1 and his wife, their daughter and her husband (who is also person l's sister's son, and hence nephew), two of the daughter's children, and person l's wife's mother. A perfectly 'normal' pair of related nuclear families, plus one mother-in-law, one might think, although the fact that person l's wife and his daughter appear to be the same age gives grounds for suspicion that all is not as it seems on the surface.

And indeed it is not, as Fig. 3.6 shows. Person 2 is indeed person 1's current wife (and also, as it happens, his actual MMBDD), and person 3 is indeed her mother. But person 4 is the daughter of person 1 and his deceased first wife, and the two 'grandchildren' far from being person 4's children, are people who would not even be classified as kin in the Anglo-Celtic system. They are the great grandchildren of person 1's mother-in-law's deceased husband's other wife. In the local Indigenous system, these children are considered kin to person 1 . Their mother is his classificatory BC ('daughter'). He looked after her when she was a child, and now her children live in his household. 
Table 3.1 Details of dwelling J as recorded on the SIHF, 2001 Census

\begin{tabular}{lrrr}
\hline Person no. & Age & Relationship to person 1 & Indigenous term \\
\hline 1. & 56 & wife & MBD \\
2. & 34 & mother-in-law & MMBD \\
3. & 70 & daughter & BC \\
4. & 34 & nephew & ZC \\
5. & 38 & grandson & BDC \\
6. & 5 & granddaughter & BDC \\
7. & 10 & & \\
\hline
\end{tabular}

Fig. 3.6 Dwelling J: actual relationships of usual residents

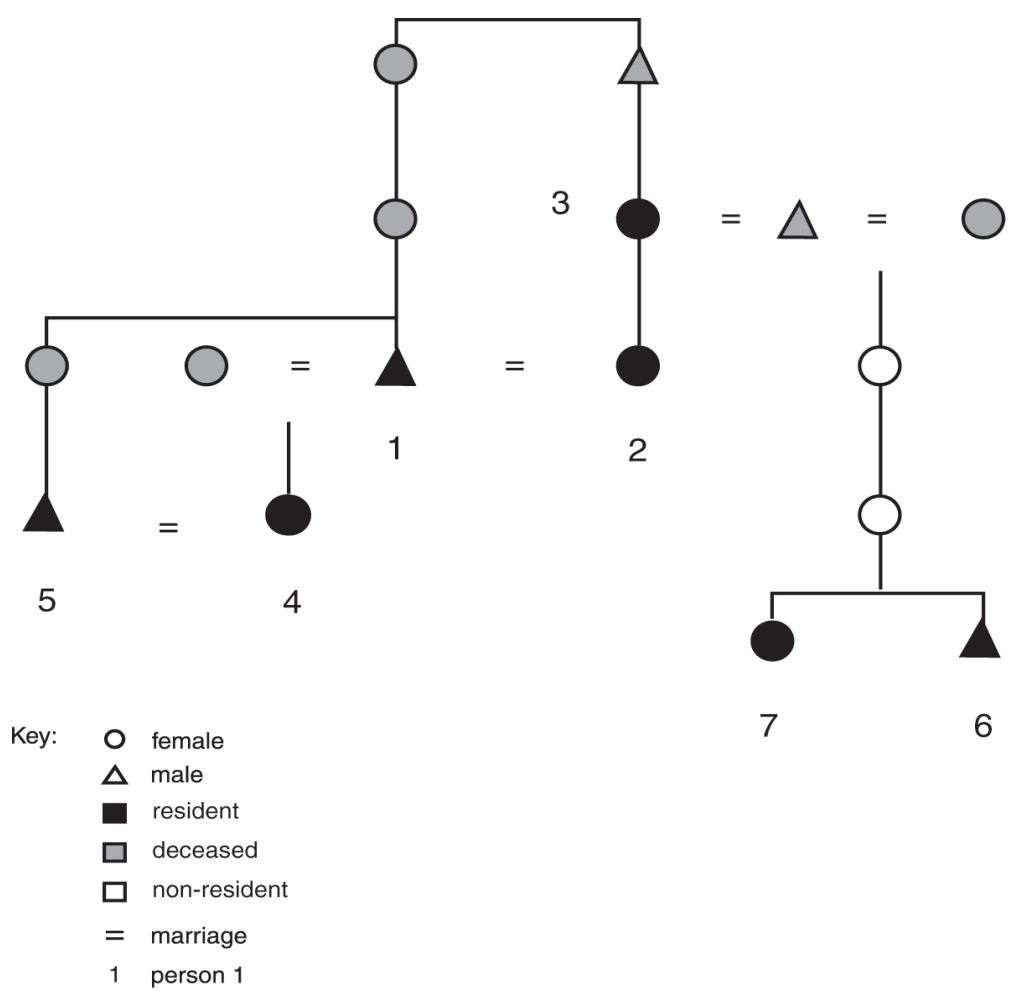


Another possible scenario in cases where a dwelling contains people who are kin in the Indigenous system, but not according to the Anglo-Celtic system, is demonstrated by the case of dwelling K. A partial genealogy for this dwelling is given in Fig. 3.7. This dwelling had 11 'usual residents'. In one case the Anglo-Celtic kin term entered in response to Q. 4 differed from the one entered on the SIHF: person $5 \mathrm{v}$ (a woman) was put down as 'uncle' on the SIPF and as 'daughter' on the SIHF. Person 10 (an 8-year-old boy) was put down as 'sister's son-in-law'. Person 8 was put down as 'brother-in-law' and his wife, person 9, as 'granddaughter'. Person 6 was put down as 'great-granddaughter'. In terms of the kinship diagram, and the Anglo-Celtic system, these responses seem to be not only wrong, but also incomprehensible. However, if the Indigenous system is taken into account, sense of a kind emerges. These answers represent an attempt, from a local Indigenous viewpoint, to translate from the Indigenous system to the Anglo-Celtic.

In the Indigenous system, person $5 \mathrm{v}$ is person l's $\mathrm{M}$. The enumerators realised, however, that this person would not be classified as mother in the Anglo-Celtic system. On the SIHF, in attempting to solve the problem, the enumerators seem to have inverted the relationship: 'daughter' is probably a translation of ZC, which is what person $5 \mathrm{v}$ calls person 1 . On the SIPF another solution was adopted: 'uncle' is the English term that locals most often use to translate MB (mother's brother). Person 6 is another M. Again, the enumerators realised that mother was not the appropriate Anglo-Celtic term. They aimed for an Anglo-Celtic term that picks out an $\mathrm{M}$ of a lower generation-but overshot by two generations. ${ }^{16}$

\section{Fig. 3.7 Dwelling K: actual relationships of usual residents and visitor}

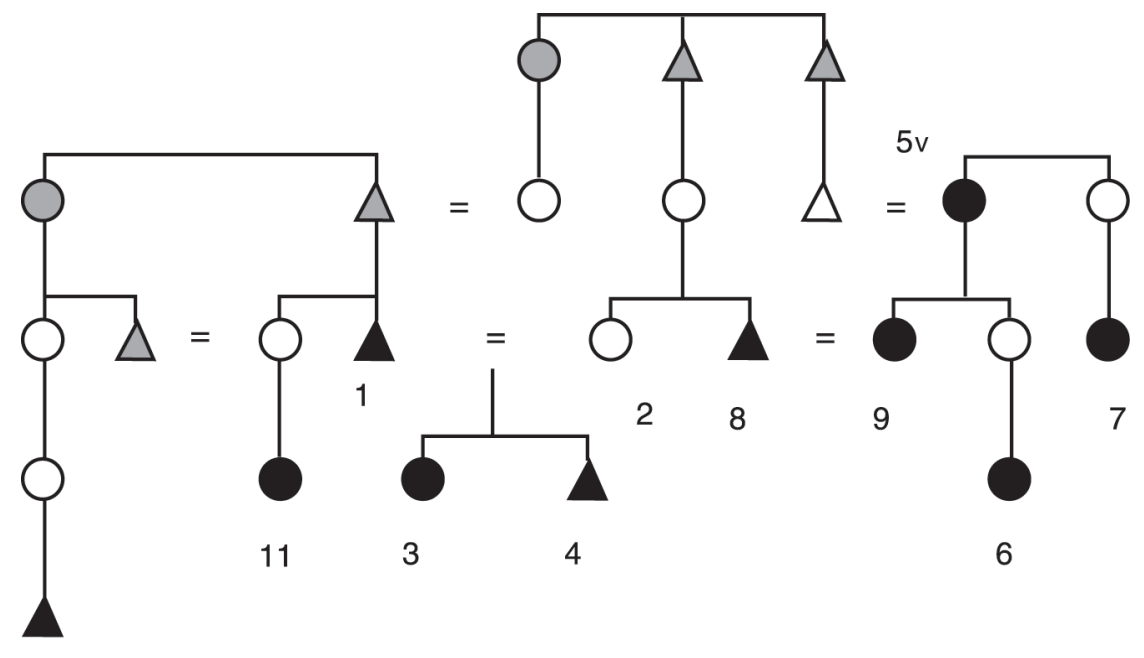

10

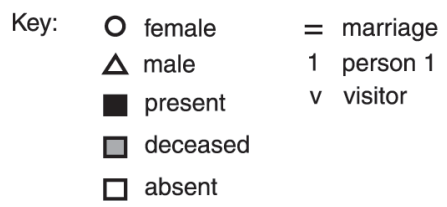


'Sister's son-in-law' (as person 10 was described on his SIPF) was an attempt to translate the term (Z)DCFZC. The enumerators nearly got it right, but again they missed a generation. One possible rendering of (Z)DCFZC is 'sister's daughter's (potential or actual) son-in-law'. ${ }^{17}$ Person 11 is person l's sister's daughter. Person 1l's as yet non-existent daughter would be person 10's MMBDD, and thus also his MBD, or potential wife.

In the case of person 9, the enumerators, perhaps suffering themselves from kinship fatigue at this point, attempted to opt for a 'straight' translation between the two systems. Person 8 is person 1's wife's brother, and so like her is person l's MBC. This was 'correctly' translated as 'brother-in-law'. In the local system, the wife of a male MBC (i.e. person 9 in this case) is MM - a type of 'grandmother'.

Every single enumeration that I observed produced results of the kind described above. The census data, if coupled with the ethnographic data, offer a fascinating insight into the local Indigenous kinship system and principles of household formation, and into how local people think about and abstract principles from their kinship categories. But as raw data on household structure they are unusable, for two reasons. Firstly, the incommensurability of the two kinship systems results in 'relationship' data that reflects neither system, and which cannot be used to construct 'families' within households. Secondly, the implicit model upon which ABS household structures are predicated- the nuclear family - is a bad model for local Indigenous households in particular and, it could be argued, for Indigenous households in general.

\section{The nuclear family deconstructed}

The problem lies in the assumption that the nuclear family is a 'natural' structure that forms the basic social and coresidential unit in all cultures. Anglo-Celtic cultures tend to take the nuclear family as the 'norm', and to describe all other household types as variations on, or deviations from that norm. The ABS, as an institution of the Australian Anglo-Celtic mainstream, reflects that tendency in its definitions. The Anglo-Celtic kinship system, with its unique reciprocal terms for the members of the nuclear family, reinforces the view of the nuclear family as somehow 'natural'. In Fig. 3.8, each interior box surrounds an ego. The terms within the box are those by which other members of the Anglo-Celtic nuclear family address ego. The nuclear family and its constellation of relationships only comes into being with a marriage: any ego is likely to be a member of more than one nuclear family in their lifetime, first as a child (family of origin) and then as a parent (family of procreation). 
Fig. 3.8 Anglo-Celtic kinship terminology and the nuclear family

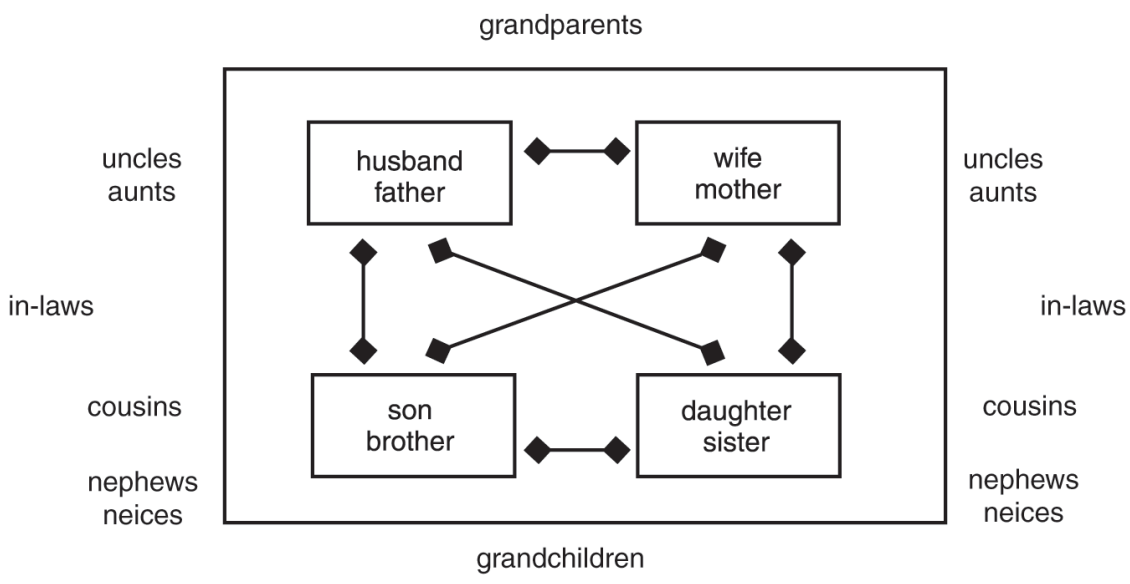

Key:

links reciprocal kin terms

The local Indigenous kinship system, in contrast, privileges lineages, not nuclear families (Fig. 3.9). Ego and ego's siblings are not primarily constituents of a nuclear family, but a point of intersection between an already existing patrilineage and matrilineage.

Fig. 3.9 Local Indigenous kinship terminology and the intersection of lineages

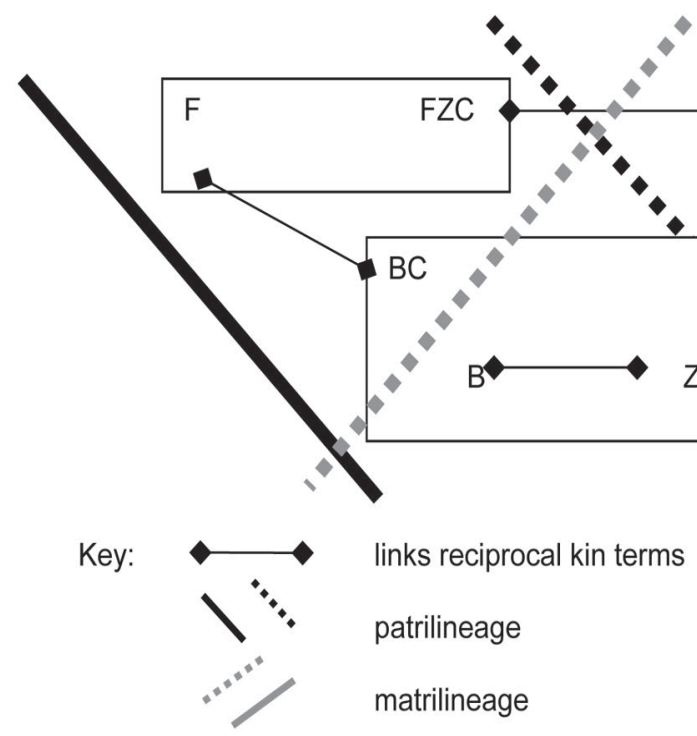


The box in Fig. 3.9 does not represent an individual ego, but rather a contains a set of relationships that are constituted by the intersection of a patrilineage and a matrilineage in a particular generation. These relationships exist independent of any particular marriage because the FZC- $\mathrm{MBC}$ relationship between two people exists before a marriage does, and every person has many FZC and MBC. In Fig. 3.9 it is simply impossible to draw a box around a set of reciprocal terms that apply exclusively within a 'nuclear family'. ${ }^{18}$ The siblings in the bottom box are $\mathrm{BC}$ with respect to their patrilineal parent, and ZC with respect to their matrilineal parent. The terms for sibling ( $\mathrm{B}$ and $\mathrm{Z}$ ) lie within the intersection of the two lineages that is constituted by the marriage.

\section{A recommendation: back to basics}

My first thoughts, as I sat observing, were that with more (and more theoretically informed) training it would be possible for local Indigenous people to produce results that would be interpretable in mainstream terms, at least for categories of kin that the mainstream system recognises as kin. Thinking in abstract terms about kinship is an everyday part of local life, and it would simply be a question of working out a systematic set of translation principles. But as I thought about it more, I began to question the premise upon which such a course of action would be based. What about kin who do not fit AngloCeltic categories? Would they be described as 'friends', or 'unrelated' - even if, in many cases they are addressed by the same kinship term as people considered to be kin in the Anglo-Celtic system? Would such a solution actually reflect the reality of the composition and dynamic of Indigenous households? It would not. It would simply represent an attempt to distort the Indigenous system by squeezing it into the mainstream Anglo-Celtic mould. And this particular local system is only one of many systems of kinship in Indigenous Australia. The same process would have to be implemented Australia-wide. This would be expensive, time-consuming, and logistically complex, if not impossible.

The better (and cheaper) course is to go back to first principles: for whom and for what purpose are these data on household composition being collected? The important generalisations that are being sought for comparative purposes concern the size of households in relation to the size of dwellings, their age and sex profiles, and whether or not people consider themselves to be related. It is not necessary to model this information in terms of nuclear family structure. Indigenous people tend to live in large multigenerational households, in which everyone is considered kin to everyone else: that is, in extended family households. This has been amply demonstrated in the literature (for recent and relevant data see Henry \& Daly 2001; Musharbash 2001; Smith 2000a). The census cannot hope to uncover the difference and complexity of the local Indigenous kinship system, or any other Indigenous kinship system, in two questions, and it should not be attempting to do so. The number of persons in the household and the range of people's ages, would be enough to indicate whether or not Indigenous people are living in households that approach or diverge from mainstream norms. ${ }^{19}$ If more fined-grained detail about particular sectors of the population is considered important, then those specific subgroups of the population could be targeted. For example, if ascertaining whether children are living in the same households as their 'real' parent(s) is considered 
important, then there could be questions targeted at those under 15 years old (and these could appear later in the form, after the question about age), asking whether their 'real' or 'actual' mother and/or father live in the dwelling.

Removing the emphasis on kinship would serve another valuable end. The case of the 'missing persons 1' highlights the central importance of kinship in local Indigenous life. To give it prime place on the census forms is to give people the impression that it is more important than anything else on the form, whereas, in fact, it is simply being used as a means to model certain kinds of demographic data.

\section{Factors influencing the quality of the data}

In the case of household structure and composition, the 2001 Census might be deemed guilty of trying too hard to accommodate the difference of Indigenous households. It failed in that it did not divorce itself sufficiently from the culture-specific categories of the AngloCeltic mainstream. The quality and interpretability of most of the data collected on the SIPFs are influenced systematically by the lack of knowledge and understanding in the wider society (as represented by the ABS) about the nature of Indigenous societies, and the ways in which they differ from 'mainstream' society. This is manifested in:

- the design of the forms and the manner in which the questions are presented;

- the content of some of the questions.

Equally significant is a corresponding lack of understanding on the part of local Indigenous people of the workings of mainstream society and of the intent behind the census, as it is reflected in the questionnaire. This is manifested in:

- a tendency to devote most effort to answering questions which are salient to them, and least effort to those which appear irrelevant;

- the misunderstanding of certain questions, resulting in answers very different from those that were intended to be elicited.

Some of these misunderstandings arose from the language used in posing the question (which could be seen as a weakness in the design of the questionnaire); others had their basis in cultural difference. Some were a combination of these, for context often provides clues to interpretation of language, and if the context is not understood then interpretation of language becomes harder. These issues could be addressed in the training of the enumerators, provided that the trainers were fully aware of what the potential problems might be.

The level of misunderstanding may have been exacerbated in the case of community A because the enumerators had not been fully familiarised with the SIPF before they started work. However, I do not think this was the most significant factor. As El said to me after the enumeration: 'we didn't really know the form at first, but we learned as we went along how to do them'. 'Training by doing' is the preferred local style: people are accustomed to learning in this way and are adept at it. 
I turn now to a more detailed consideration of the data that were collected on 'age', 'place of residence', 'education', 'origin and ancestry', 'culture' (as measured by language use and religious affiliation), and 'work'. I will touch on several themes that bear on the quality of the data: the design of the form and of the questions, the content of the questions, and the relevance of some of the questions. For some of them prompt two questions in response. What is the purpose of this question? Who are these data being collected for?

\section{How old are you?}

Whereas most, if not all, non-Indigenous Australians know the precise date and year of their birth, even if they cannot remember their closest relatives' telephone numbers, exactly the reverse is true of most local Indigenous people. It is a question of what it is considered important to remember. The enumerators made valiant efforts to ascertain people's ages, and El was intending to check the answers later against the clinic records. I do not know if this actually happened, but if it did, it would still not have resulted in accurate date-of-birth information from some people, particularly the older ones. For example, one man gave his age (emphatically) as 63. His driver's licence records his birth date as 01/07/45, and the HA clinic records have his birth date as 01/01/48. Many older people have the first of January (or the first of July) as their birthday in the clinic records and on official documents. It can safely be inferred that such 'dates of birth' are guesstimates made by missionaries and other local record keepers.

There are local terms which designate degrees of maturity, or stages of life: [baby], [child], [circumcised boy], [prepubescent girl], [young man], and so on. Some terms from the mainstream have also been adopted locally, for example 'preschooler', 'schoolkid', and 'pensioner'. These terms all relate indirectly to age ranges. It might be better, therefore, to ask this question in a different way, giving people a choice of boxes to mark according to whether they were $0-5,6-10,11-15$, and so on. It would be possible then, in training, to get the enumerators to match these up with the local terms for particular life stages. These could then be used to elicit the age data from the interviewees. ${ }^{20}$

\section{‘Place' of residence}

Because the census is focused on the dwelling as the unit of analysis it cannot capture relationships between people who live in different dwellings. Does this matter? Every analyst who uses census data is aware that it is, above all, a dwelling-based survey and that it does not seek to provide data on inter-dwelling relationships.

However, many analysts may not be aware that Indigenous households can and sometimes do have members in more than one dwelling. In community A, as in many other Indigenous communities, the households of certain dwellings are linked closely to one anothereconomically as well as by ties of kinship. This is particularly true of dwellings containing a man and dwellings of the wives with whom he is not presently cohabiting. The people at community A rejected 'separated but not divorced' as the correct box to mark for this scenario. The SIPF is neutral on the question of polygamy (either by design or by accident). It is not possible to answer the question on marriage (Q. 6) in a way that indicates how many wives a man has, or how many co-wives a woman has. As we have seen, at 
community A there are, apparently, two dwellings where person 1 is a married woman with children, but where there is no 'husband' on the scene. These data might be interpreted to indicate the presence of 'single parent' households, with all that this implies in mainstream society. This would be a misinterpretation, since these are not deserted and disadvantaged women struggling to raise their children in isolation. They and their children are part of an extended family that happens to occupy more than one dwellingand indeed it is not uncommon to find some of the children of one co-wife living in the dwelling of another.

The dwelling is not the salient 'unit of residence' at community A; rather the community itself is. This much was clear in the enumerators' and respondents' reactions to Q. 7-9, with the recurring demand for postal addresses. Even larger communities such as B are almost invariably divided into recognised sub-communities or 'camps' (e.g. Top Camp, Bottom Camp). The design of the SIPF should perhaps acknowledge this fact, by using 'community' or 'sub-community' instead of 'place' and by eliminating requests for postal addresses. The subdivisions of big communities could be identified as part of the training of the enumerators.

The data collected at community A on where people were living one and five years ago are almost certainly unreliable. One problem is the concept of ' $\mathrm{X}$ number of years ago', since local people do not measure their lives in such terms. Solutions to this problem might be found in the training of the enumerators, as in the case of the 'age' and 'place' questions. It might simply be a matter of impressing upon them that the ABS considers this information to be important, and devising more appropriate, locally salient cues, such as particular memorable events that were of importance to community members. ${ }^{21}$

There is another, more intractable problem: for local people, these questions about 'place' are not value-free, as they are for most non-Indigenous Australians. Place is not just physical space. People have strong spiritual and emotional attachments to particular places, and if they are now living at one of those places they are more than likely to state that this is where they have always lived 'most of the time', thus understating their mobility.

\section{Ancestral connections}

The questions on origins and ancestry need rethinking. In their present form they are underpinned by covert distinctions - 'Indigenous' as opposed to 'ethnic' as opposed to 'unmarked' (Anglo-Celtic mainstream). Of these, the 'Indigenous' is the most marked, because it is referred to in two separate questions, and the Anglo-Celtic mainstream is so 'unmarked' that it is not even mentioned. From the Indigenous perspective this makes no sense, and although the responses were accurate - or appeared to be - the questions were felt to be decidedly odd. For Indigenous people, 'Indigenous' is the unmarked category, and the Anglo-Celtic mainstream is the most marked, because it is the most common source of non-Indigenous ancestry for local Indigenous people.

What precisely is the information being sought by the question on origin? It is not clear to me, and it certainly was not clear to the local Indigenous people. Is it another question about ancestry in a different guise, or a question about self-identification? 


\section{What is a language?}

It is important for the designers of the IES to be aware of issues that are potentially loaded in a political sense. The bilingual education program in the Northern Territory was recently under real threat. One argument that can be used to challenge the viability of such programs is that it is just too difficult to cater for communities where many different languages are spoken. This is not an argument that can seriously be mounted at communities where the language in question is spoken, but the data from the 2001 Census, in the hands of non-specialists, could be used to support this argument. It would have been a simple matter to instruct the enumerators to enter the term that has been coined for the language (by linguists) as the language spoken by all speakers of a dialect of that language. In terms of providing salient information for policy-makers this would have been the best option (although for the sociolinguist the data that were actually collected are much more fascinating).

The 2001 data issued by the ABS in its first release indicates that nearly 20 per cent of Indigenous respondents at HA outstations said they spoke 'English only'. This does not correspond in any way to reality: I can think of no local Indigenous individual in this region who does not speak an Aboriginal language as their first language.

\section{'Religion' and 'beliefs'}

If the question on religion had carried the explicit instruction that more than one box could be marked, the answers would have been a more accurate reflection of the situation at community A. The term 'Traditional Beliefs' carries an implicit value judgment: beliefs do not have the same status as religion unless they are regarded (and described) as a 'belief system'.

The data in the first ABS release of the 2001 Census indicate that fewer than 40 per cent of the Indigenous population of the HA outstations marked 'Traditional Beliefs' as their religion. This does not accord with my own observations of the Indigenous people of this region, who continue strongly to maintain their traditional belief system and their ceremonial life. The design of the question on the SIPF almost certainly materially influenced the response.

\section{Education: what's in a name?}

Most of the questions on schooling and further training and education were difficult for community A enumerators and residents to understand and answer, and this generalisation probably holds for many Indigenous communities in 'remote' Australia. Yet arguably, accurate and interpretable data are vital for policy formulation in this area, which will have a strong influence on the future wellbeing and self-sufficiency of discrete Indigenous communities. No matter how the questions are formulated, the training of the enumerators needs to focus on their content. The enumerators need to be given the knowledge to interpret the responses of the interviewees, most of whom have not received formal education past the primary level of schooling. Those who have further training of some sort mostly fall into the category 'Yes, other course' in Q. 23. In such cases it should be possible to sidestep the next four questions. 


\section{'Work' and CDEP}

Most adults at community A are on CDEP. The status of the CDEP as a provider of 'real work' is politically contested (see e.g. Shergold 2001). The SIPF for the 2001 Census unequivocally equates CDEP with other kinds of work, starting at Q. 29 with the question: 'Did you have a paid job last week?' and providing a box for 'Yes, worked-CDEP'. In the questions which follow, almost to the end of the form (Q. 30-38), the interviewee is led, inexorably, further down this path. The SIPF makes valiant attempts to keep all these questions relevant to CDEP 'jobs' but the effort shows, for example in Q. 34: 'What work does your employer do? (If worked for CDEP write 'community council')'.

The way in which these questions are put creates a double bind for local people, because CDEP is not primarily payment for work in the outstation context - at least not for the kind of work contained in the prompts to Q. 30. CDEP payments are nevertheless vital to people who live on outstations, since they are the main source of regular cash income. It is therefore quite unsurprising that the answers to the questions on 'work' were formulaic.

Although the 'rubbish collectors' certainly keep this particular community clean and tidy, the job does not represent 20 hours of work per week for several young men. The inference that may be drawn by some is that CDEP is 'sit-down' money. The inhabitants of community A do not spend an undue amount of time sitting around doing nothing, but the prompts for Q. 30 create no space for people to mention the work that they spend most time doing. A point made by Diane Smith is pertinent here:

Serious problems arise for government policy and programs, and for their clients, when supposedly objective statistical data do not adequately represent, or only partially represent, social and economic realities. Associated with such difficulties is the tendency to dismiss as unimportant those processes and behaviours which we do not know how to measure by standard measures (1992: 68).

Hunting and gathering are daily activities for most young 'rubbish collectors' at community A. And if these are implicitly discounted as work, how much more so is working for the community during ceremonial performance? The same young 'rubbish collectors' spend sometimes up to six hours a day dancing energetically and skilfully in the hot sun, for days at a time. Such skills, and prowess at hunting and fishing, are the product of long hours of learning and practice, and the work that results contributes significantly to the physical and cultural wellbeing of the community. The focus in the SIPF on the mainstream notion of 'work' devalues these 'traditional' forms of work. The failure to provide a space for their inclusion does two things: it implies that this kind of work does not contribute to the economic and social wellbeing of the individuals and their community, and it allows those who are so minded to characterise Aboriginal people as getting 'something for nothing'.

There are two possible solutions. If CDEP is categorised as work, then traditional forms of work, such as hunting, fishing, collecting bush tucker and making art should be included in the prompt to the question: 'What job did you do?' And it should be possible to list more that one job. 
Alternatively, CDEP in places like community A should perhaps be uncoupled from the notion of work in the mainstream sense, and from the labour force statistics. A desirable side effect would be that the SIPF, for people on CDEP, would be much shorter. If this solution were adopted there should be an additional question on the SIPF that allows people to estimate the extent and nature of their 'unpaid' work. Art and craft production, which is one of the only other significant sources of cash income, should be included in the prompts for non-CDEP work: its presence might cause (a few) people to reflect a bit more closely on the sources of their cash income, and to make some effort to record them.

\section{Conclusion}

The effectiveness of the IES can be measured according to several criteria. The strategy for the recruitment of the Indigenous enumerators appears to have been effective, particularly when one bears in mind the disruptions that occurred. The strategies for eliminating under-enumeration and double counting were about as good as they could be, in circumstances that are inherently extremely difficult. Some fine-tuning in these areas is probably possible and desirable, but radical rethinking is not required.

Because I was not able to observe a training session, and because the training of the enumerators at community A was curtailed, it is difficult to comment directly on training procedures and content, and their effects. In the recommendations below I suggest quite radical changes to the form and content of the SIPF. If implemented, the training of the CFOs and enumerators would need to change in any case, and therefore:

- I would strongly recommend that any new version of the SIHF and/or SIPF be pretested in the field in a range of communities, using as enumerators people who were employed as enumerators in the 2001 Census. They, in conjunction with a CFO who had also taken part in the 2001 Census exercise and an anthropologically-trained observer would be in the best position, between them, to evaluate the form and make recommendations for any further refinements. Such an exercise could also act as a pilot for new training procedures. Such training should focus as much on the contents of the questions on the SIHF/SIPF as on procedural matters.

Detailed recommendations concerning the form and content of the questions have been made throughout the second half of this paper. The following, more general, recommendations flow from them:

- The SIPF is much too long. Administering it was an onerous task for the enumerators, and this encouraged formulaic responses to certain questions, particularly ones whose purpose was opaque to local people, or which were worded or structured in ways that made them hard to interpret.

- The presence of questions on kinship at the beginning of the SIPF, and the fact that they also appeared on the SIHF, gave them undue emphasis. Because kinship is such a salient topic for local people, they took this as a signal that these were the most important questions to address, and more time was spent on Q.4, and on thinking about how it should be answered, than on any other question. I have suggested that the idiom 
of kinship be dispensed with in eliciting information on household composition, and that a new type of extended family household be added to the inventory of ABS household types.

- The SIHF and the SIPFs for the dwelling should possibly be combined, as they are in the 'mainstream' form. However, the summary information gathered on 'absent usual residents' and 'visitors' is valuable, and should be retained. The SIHF might be retained as a separate document, but in another guise, as a 'household checklist'. This is how it was used by the enumerators at community A, and it proved a useful tool.

- The layout of the SIPF needs attention. The use of large, bold print versus small print should be carefully reviewed, bearing in mind that many Indigenous people (including many enumerators) are not fluent readers of English. The repetitive demands to supply postal addresses (for dwellings and places of work) should be circumvented.

- The design of the pathways through the form also needs some further thought. One possibility is to uncouple CDEP from the labour force data so that CDEP participants do not have to answer numerous questions about their 'work'. The questions on further education and training could also be streamlined.

- More thought should be given to devising questions that allow 'non-mainstream' aspects of Indigenous social life to emerge from the data. In some cases this simply involves putting more thought into the prompts to a question, to allow a wider range of options in the response. The overall impression given by the data on the SIPF is that the people of community A 'lack' certain things in comparison with the mainstream - education and 'real jobs' in particular. If the concept of Australia as a multicultural society is to be taken seriously, then an instrument such as the census should be attempting to capture, as far as possible, significant features of nonmainstream cultures that the mainstream culture lacks, particularly those that influence interaction with the mainstream in significant domains such as welfare, employment and education.

- Further to this, a certain amount of 'deconstruction' of mainstream categories would not go amiss. The 'nuclear family' is a case in point. Another is the way in which different sectors of the population are categorised in the questions on 'origin' and 'ancestry'.

Many of these suggestions, if taken up, would result in a shorter and more 'culture-specific' form, tailored to those Indigenous people who live in discrete communities on or near their traditional 'country', with limited or no access to the labour market. These are communities where the major organising principle of social life is kinship, where households tend to be large, compositionally complex, multi-generational and somewhat fluid in composition because of high levels of individual mobility, and where non-mainstream forms of 'work' make an important contribution to the local economy and to cultural life. This might, perforce, narrow the scope for the administration of the IES by enumerators. Other 
Indigenous people might be candidates for a self-administered IES form, or would be required to fill in the mainstream form, with help from an enumerator if needed.

Such a strategy would not be without its own problems: Indigenous Australia was never homogeneous, and the contemporary situation there is even more diversity as a result of the vagaries of the colonial process and the uneven penetration of the settler culture and its institutions. The terms 'remote', 'rural' and 'urban', with which the settler society attempts model this diversity, once reflected a certain logic of distance. Today, however, these terms are becoming increasingly metaphorical. A 'remote' community may find itself cheek by jowl with the company town - and the mine - of a multinational enterprise. 'Rural' Kuranda and 'remote' Yuendumu are different in many respects, but have a 'number of fundamental commonalities', including the fact that: 'the concept of "family" based on the extended family formation is the central and abiding social and economic construct, and a key component of individual identity' (Smith 2000b: 95). The ABS would have to assess each region, each community within a region, and even individuals within communities to determine which was the most appropriate means of enumeration for them. But the result would be a far higher proportion of self-administered forms, and the collection of much more reliable and relevant data on a sector of the Australian population that will continue to be not only highly distinctive but also in great need of well informed state policy and programs.

\section{Notes}

1. CHINS provides an estimate of the service population rather than a census-style head count. CHINS estimates invariably, therefore, produce larger populations than does the census enumeration.

2. It may have been a deliberate strategy to give E4 this house, but unfortunately it did not occur to me to check this. At the time the dwellings were apportioned I was not aware of the potential problem.

3. This process sometimes presented a challenge to my position as a neutral 'observer': it was hard for the enumerators not to cast me as a 'helper'. From the time of the 'training' session onwards I was appealed to intermittently for clarification on particular questions. I resisted giving advice as best I could (by pleading ignorance, and saying they should ask the CFO or the CC), except in the area of the translation of kinship terms. Here I simply followed where they led: they were bent on devising English 'translations' for local kinship terms that have no English equivalents, rather than classifying as non-kin people whom they regard as kin.

4. Daly and Smith's discussion of the interview techniques devised for community case studies at Kuranda and Yuendumu is pertinent here: 'The social pool of people contributing as additional de facto "respondents" to each questionnaire were included in the interview process... This approach...is positively oriented to socially embedded and constructed Indigenous modes of communication where the individual cannot be effectively "quarantined" for the purposes of eliciting information' (2000: 20). The enumerators at community A were, in effect, applying the same technique. 
5. The form of Q. 2, which is not a direct question (Sex:) betrays the presence of a topic that the compiler of the questionnaire (presumably a member of the Euro-Australian mainstream), found inappropriate as the subject of a direct question. None of us is free of cultural taboos.

6. From day two onwards, El took a calculator with him. When someone knew their year of birth, this was subtracted from 2001, and the answer was recorded as the person's age.

7. Most local marriages would be classified as de facto relationships in mainstream terms, but it would be quite inappropriate, in the view of local Indigenous people, to classify them thus. The category 'de facto' occurs neither on the SIPF nor on the mainstream SIHF, and perhaps the injunction "'Married" refers to registered marriages', which does not appear on the SIPF, should also be removed from the mainstream HF.

8. The word Dreaming is not used in this area, but the word translated here as 'sacred ancestral inheritance' corresponds more or less to what mainstream Australia understands by that concept.

9. In contrast to the situation in some other parts of Australia (see David Martin, this volume), local people in this area attach no cultural value to fluency in English. Being able to speak English is seen as a useful skill, but inability to do so is not valued negatively.

10. The actual amount of money that people get in their account each fortnight varies, because the HA deducts money from people's CDEP payments to cover their outstanding bills before crediting the remainder to their account.

11. The fourth box in Q. 29 refers to 'sorry business' as a possible reason for being off work. People in this area do not use this phrase to describe funerals, and I suspect that there are other places in Australia where it is also an unfamiliar usage. It would be better to use a standard English term such as 'funeral'.

12. I was told this by one of the absent 'usual residents'.

13. The 2001 Census Dictionary (ABS 2001) defines a person's usual residence as the place where the person 'has lived or intends to live for a total of six months or more'.

14. When I returned to community A in June 2002, at least one tent which had been erected just after the census enumeration in 2001 was still in place outside its associated dwelling. It had acquired a protective awning consisting of a large tarpaulin on a bush timber frame.

15. This is not to say that people do not distinguish between their actual mother (and other 'close' M such as their mother's sisters) and other $M$, in terms of sentiment and behaviour.

16. In the great-grandchild's generation, female children are merged under the terms $M$ or $\mathrm{FZ}$, depending on the patrilineage to which they belong. 
17. As mentioned previously, El and I had several conversations about how to translate (Z)DCFZC. On one occasion he reasoned that the reciprocal term MBCMM means 'mother-in-law's mother', so in English its reciprocal term should be 'mother-in-laws' son's son-in-law'. This actually works for a MBCMM and a male DCFZC, but whereas El made the computation instantly in his head, I had to go away and puzzle over a kinship chart for some time to confirm it for myself. This is not necessarily because El is smarter than I am (although that may well be true). Rather, a 'first' kinship system is like a first language: the individual 'born into' the system carries its grammar unconsciously in their head. A 'second' kinship system is like a second language: the rules must be learned consciously and laboriously, and full fluency is extremely hard to achieve.

18. Many other features of the kinship terminology support the thesis that a major organising principle of the system is the relationship between lineages over time. These will be discussed in another paper.

19. Diane Smith (pers. comm.) suggests an alternative strategy: getting the enumerators to draw up genealogies for each dwelling. In this way, household structures would be recoverable in finer detail. However, such a strategy would require extra training for the enumerators, would add to the time that it takes to complete the SIHF, and would be easily implemented only in communities where the enumerators were well known to the interviewees, and where the enumerators themselves were familiar with the details of how everyone was related to each other. Moreover, a small proportion of local people are in 'wrong' marriages, or are the children of such unions, and such information has to be treated carefully. While everyone in a community is aware of such facts, it is not usual or acceptable to discuss them openly in public.

20. Roger Jones (pers. comm.) doubts whether this would produce data that was any more accurate. However, an 'age-range' as opposed to an 'exact age' question would be more in tune with how local people view the question of age, and the results would certainly be no less accurate.

21. The local language distinguishes six seasons in the year; 'dry season' is not one of them. For most locals the year of the last census would not be memorable for that particular reason. 